\title{
Metal-Ligand Cooperative Proton Transfer as an Efficient Trigger for Rhodium-NHC-Pyridonato Catalyzed gem-Specific Alkyne Dimerization
}

\author{
María Galiana-Cameo, Asier Urriolabeitia, Eduardo Barrenas, Vincenzo Passarelli, \\ Jesús J. Pérez-Torrente, Andrea Di Giuseppe, Víctor Polo,* and Ricardo Castarlenas*
}

Cite This: ACS Catal. 2021, 11, 7553-7567

Read Online

ACCESS | Lلll Metrics \& More | 回 Article Recommendations ｜ sl Supporting Information

ABSTRACT: The mononuclear square-planar $\operatorname{Rh}\left\{\kappa^{2}-X, N-(\mathrm{Xpy})\right\}\left(\eta^{2}\right.$-coe $)(\mathrm{IPr})(\mathrm{X}=\mathrm{O}, \mathrm{NH}$, $\mathrm{NMe}, \mathrm{S})$ complexes have been synthesized from the dinuclear precursor $\left[\mathrm{Rh}(\mu-\mathrm{Cl})(\mathrm{IPr})\left(\eta^{2} \text {-coe }\right)\right]_{2}$ and the corresponding 2-heteroatom-pyridinate salts. The Rh-NHC-pyridinato derivatives are highly efficient catalysts for gem-specific alkyne dimerization. Particularly, the chelating N,Opyridonato complex displays turnover frequency levels of up $17000 \mathrm{~h}^{-1}$ at room temperature. Mechanistic investigations and density functional theory calculations suggest a pyridonato-based metal-ligand cooperative proton transfer as responsible for the enhancement of catalytic activity. The initial deprotonation of a Rh- $\pi$-alkyne complex by the oxo-functionality of a $\kappa^{1}-\mathrm{N}$-pyridonato moiety has been established to be the rate-limiting step, whereas the preferential protonation of the terminal position of a $\pi$-coordinated alkyne accounts for the exclusive observation of head-totail enynes. The catalytic cycle is closed by a very fast alkenyl-alkynyl reductive elimination.

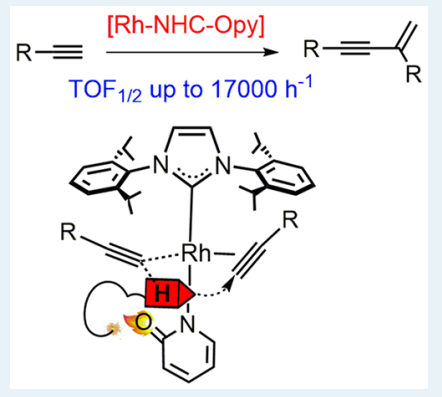

KEYWORDS: metal-ligand cooperation, ligand assisted proton shuttle, alkyne dimerization, N-heterocyclic carbene, DFT calculations, hemilability

\section{INTRODUCTION}

Organometallic catalysis is nowadays at the central core of the preparation of elaborated organic structures owing to a continuous design of new metal-ligand architectures. ${ }^{1}$ Undoubtedly, the high levels of catalytic efficiency have been achieved due to a precise control of reactivity through detailed determination of mechanistic issues. In this context, the concept of metal-ligand cooperation (MLC) has emerged as an essential piece in organometallic-mediated bond cleavage and formation, particularly for dihydrogen activation and related reactions. ${ }^{2}$ The synergic effect arising from MLC generally triggers an enhancement of catalytic activity and provides better control of selectivity. A particular case of MLC arises when a ligand acts as a carrier for a proton from one substrate to the other for which the term ligand assisted proton shuttle (LAPS) has been coined (Scheme 1). ${ }^{3}$ Besides its competence in the originally proposed alkyne-vinylidene tautomerization, ${ }^{4}$ LAPS pathways have been proposed in catalytic intramolecular cyclizations ${ }^{5}$ and stoichiometric intermolecular reactions, ${ }^{6}$ but scarcely applied to catalytic intermolecular transformations. ${ }^{7}$

Alkyne dimerization is a practical and atom economical access to 1,3-enynes as key structural elements in a variety of biologically active molecules and functional organic materials. ${ }^{8}$ Efficient catalysts spread across the periodic table, from $\mathrm{f}$ block, ${ }^{9}$ early ${ }^{10}$ or late transition metals, ${ }^{11}$ to main group elements. ${ }^{12}$ Moreover, earth-abundant transition metals of the first row ${ }^{13}$ or organocatalysts ${ }^{14}$ have recently emerged. Due to the inherent rich chemistry of alkynes, the formation of headto-tail $(\mathrm{gem})$ or head-to-head $(E / Z)$ enynes is commonly in competition with the formation of a myriad of oligomeric, polymeric, or cyclic organic structures. Therefore, despite the fact that remarkable advances in the selective preparation of $E^{11 \mathrm{~b}, \mathrm{~g}, 13 \mathrm{~b}} Z \mathrm{,}^{9 \mathrm{c}, 10 \mathrm{~b}, 13 \mathrm{c}, \mathrm{e}}$ or gem-enynes, ${ }^{13 \mathrm{~d}, \mathrm{f}, \mathrm{i}, 14 \mathrm{a}}$ further research effort is still desirable, particularly in mechanism elucidation.

Four general pathways have been proposed for transitionmetal mediated alkyne dimerizations: ${ }^{11 i}$ (i) external attack on the coordinated $\pi$-alkyne; (ii) oxidative addition of a terminal alkyne; (iii) nonoxidative base-mediated formation of metalalkynyl species; and (iv) dimerization via a vinylidene intermediate. It has been rationalized that the nonoxidative route iii would be the preferred approach for the selective preparation of gem-enynes (Scheme 2). ${ }^{11 i}$ Initial deprotonation of the alkyne leads to metal-alkynyl species. Noteworthy, an MLC effect has been claimed in the case of an internal base. $^{11 f, 13 \mathrm{~d}, \mathrm{f}, \mathrm{g}, \mathrm{i}}$ Then, the pathway continues by an insertion of another alkyne into metal-alkynyl bond and subsequent

Received: February 9, 2021

Revised: $\quad$ May 21, 2021

Published: June 9, 2021 
Scheme 1. Catalytic Ligand Assisted Proton Shuttle

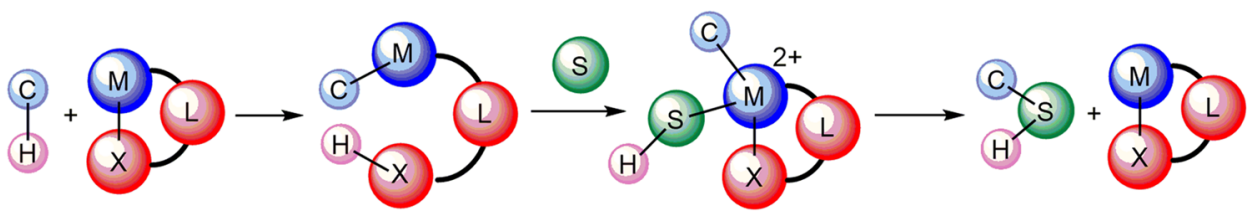

Scheme 2. Metal-Ligand Cooperative Alkyne Dimerization

\section{Proposed Alkyne Dimerization Mechanisms ${ }^{11 i}$}

\section{$\begin{array}{lll}\text { i) Attack on } \pi \text {-Alkyne } & \text { ii) Alkyne Oxidative Addition } & \text { iv) Vinylidene Intermediate }\end{array}$}

iii) Base-Mediated non-Oxidative Pathway
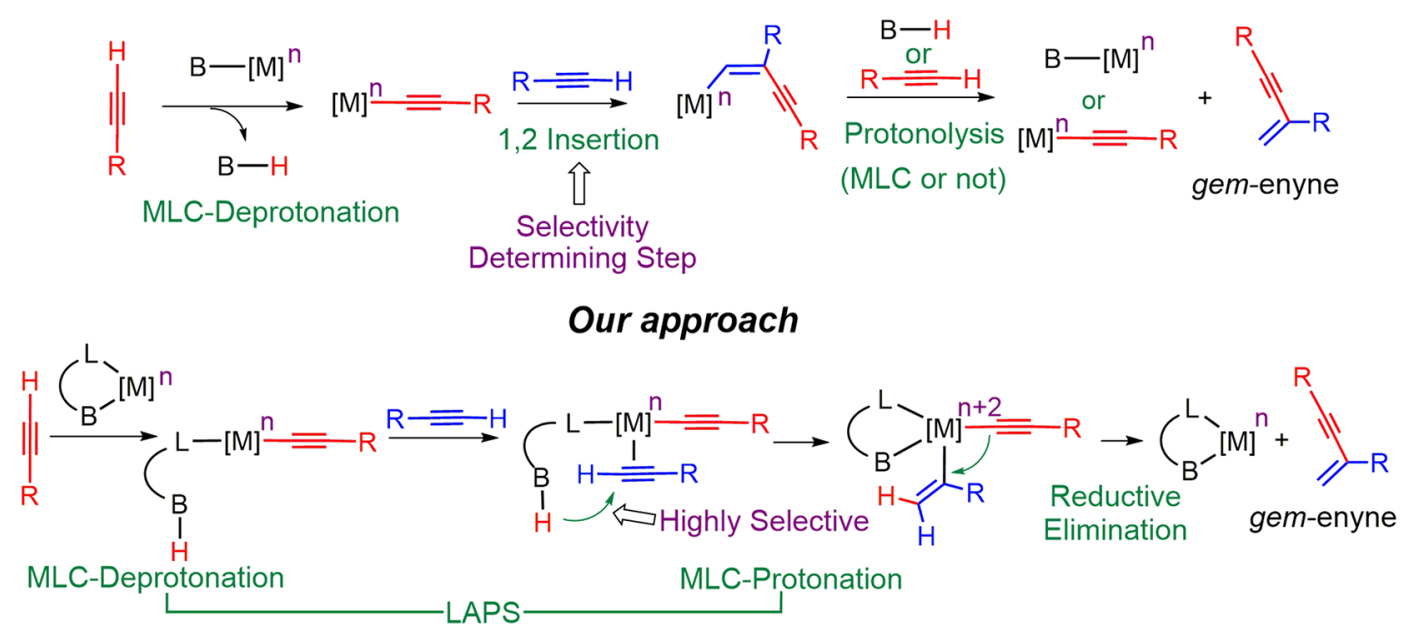

\section{Catalyst Design}

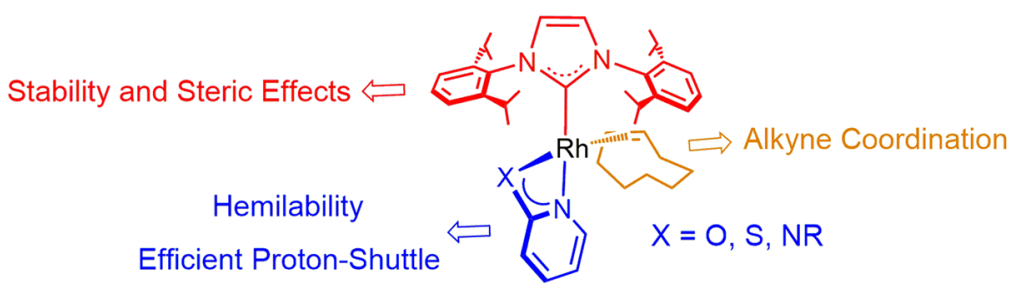

protonolysis by the conjugated acid of the initial base (MLC or not) or an alkyne itself. Although this pathway takes advantage of the benefits of MLC in deprotonation or protonolysis, the key insertion step, which determines the selectivity and is usually rate-limiting, remains excluded from the metal-ligand cooperative influence. An alternative approach can be envisaged in which metal and ligand would act in cooperation throughout the whole catalytic cycle. After the initial deprotonation of an alkyne molecule, the resulting protonated ligand could transfer the hydrogen atom to a second molecule of the alkyne in an oxidatively manner that yields a $\mathrm{Rh}^{\mathrm{III}}$ alkenyl-alkynyl species. Subsequent reductive elimination will close the catalytic cycle. An MLC effect is expected to result in lowering the key energetic barriers. Indeed, the selectivity determining step changes from a mainly sterically ligandcontrolled carbometalation in iii to a Markovnikov-type electronically and sterically favored protonation on a coordinated alkyne, therefore enhancing specific gem-enyne formation.
Recent results from our laboratories have revealed that coordination of an $\mathrm{N}$-heterocyclic carbene (NHC) ligand to rhodium complexes resulted in efficient alkyne dimerization catalysts. ${ }^{11,15}$ Several chelate 1,3-bis-hetereoatomic acidato (BHetA) ligands, such as carboxylato, thioacidato, or amidato, have demonstrated their utility as internal bases to selectively promote the formation of head-to-tail enynes. Now, along this line, we hypothesize that increasing the robustness of the chelate interaction should allow the anionic ligand to act not only as a base but also as an efficient proton shuttle. In this regard, pyridine-like moieties have previously been efficiently anchored to Rh-NHC platforms. ${ }^{16}$ Thus, 2-heteroatomsubstituted pyridine ligands appear to be promising candidates to fulfill the requirements of a BHetA structure with tight chelate coordination. ${ }^{17}$ Particularly, 2-pyridonate moieties have been shown to act as versatile proton-responsive ligands ${ }^{18}$ which can behave as powerful internal bases ${ }^{19}$ as well as efficient proton shuttles. ${ }^{20}$ Moreover, its proven hemilability ${ }^{21}$ would be key for the generation of vacant sites and the proton transfer process. Herein, we report on the preparation of $\mathrm{Rh}^{\mathrm{I}}$ - 
Scheme 3. Preparation of Rh-IPr 2-Heteroatom-Pyridinato Complexes

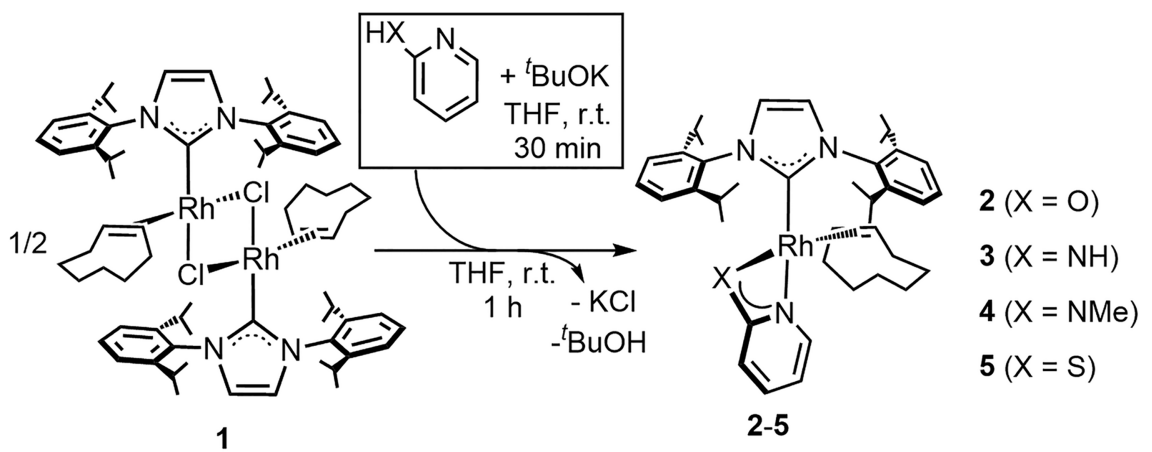

NHC-pyridinato derivatives and their application as catalysts for gem-specific alkyne dimerization. Experimental and theoretical studies have revealed a rhodium-pyridonato LAPS process as responsible for the enhancement of catalytic activity.

\section{RESULTS AND DISCUSSION}

Preparation of Rh-Pyridinato Catalysts. The dinuclear precursor $\left[\mathrm{Rh}(\mu \text {-Cl })\left(\eta^{2} \text {-coe }\right)(\mathrm{IPr})\right]_{2}$ (1) $\{\mathrm{IPr}=1,3-\mathrm{bis}(2,6-$ diisopropylphenyl)imidazolin-2-carbene; coe = cyclooctene $\}$ reacts with a THF solution of deprotonated 2-heteroatompyridine compounds to yield BHetA derivatives $\mathrm{Rh}\left\{\kappa^{2}-X, N\right.$ $(\mathrm{Xpy})\}\left(\eta^{2}\right.$-coe $)(\mathrm{IPr})\left\{\right.$ py $=\mathrm{C}_{5} \mathrm{H}_{4} \mathrm{~N}, \mathrm{X}=\mathrm{O}(2), \mathrm{NH}(3), \mathrm{NMe}$ (4), S (5)\} (Scheme 3). The new complexes were obtained as yellow-orange solids with $55-72 \%$ yields. It is worth mentioning that complex 2 can be directly obtained by reaction of 1 with 2-pyridone in the absence of an external base, although in low yield and purity. Moreover, in contrast to related 8-quinoline derivatives, ${ }^{16 a}$ no $\mathrm{O}-\mathrm{H}$ oxidative addition to yield $\mathrm{Rh}^{\mathrm{III}}$-hydride species was observed. On the contrary, the reaction of 1 with the more acidic 2-mercapto-pyridine resulted in the formation of several $\mathrm{Rh}^{\text {III }}$-hydride species, as reflected in the appearance of ${ }^{1} \mathrm{H}$ NMR highly shielded doublets. As far as we know, the coordination of the 2heteroatom-pyridinato moiety into an Rh-NHC framework is unprecedented. $^{22-25}$

The solid-state structure of the pyridonato complex 2 was elucidated by X-ray diffraction analysis. An ORTEP view of the molecule with selected bond lengths and angles is displayed in Figure 1. A mononuclear structure with a rare chelate arrangement $^{22}$ of the 2-pyridonato ligand is observed instead of the more typical $\mu$-bridge dinuclear assembly. ${ }^{23}$ The crystal structure exhibits a distorted square planar geometry at the metal center with the IPr in a cis arrangement with respect to coe $\left[\mathrm{C}(1)-\mathrm{Rh}-\mathrm{ct} 94.32(6)^{\circ}\right]$, and the oxygen atom in a trans disposition to the latter $\left[\mathrm{ct}-\mathrm{Rh}-\mathrm{O}(44) \quad 168.82(4)^{\circ}\right]$. The $\mathrm{Rh}-\mathrm{C}(1)$ bond length $[1.947(2) \AA]$ is similar to those already reported for $\mathrm{Rh}^{\mathrm{I}}-\mathrm{IPr}$ complexes. ${ }^{16}$ The imidazolinyl ring deviates from the typical perpendicular out-of-plane configuration $\left[\mathrm{N}(5)-\mathrm{C}(1)-\mathrm{Rh}-\mathrm{O}(44)-68.0(2)^{\circ}\right]$ and the calculated pitch $\left(\theta 10.1^{\circ}\right)$ and yaw $\left(\psi 1.5^{\circ}\right)$ angles ${ }^{16 \mathrm{e}}$ indicate a distorted coordination with respect to the $\mathrm{Rh}-\mathrm{C}(1)$ bond. As for the chelate ligand, it exhibits a reduced bite angle [O(44)$\left.\mathrm{Rh}-\mathrm{N}(38) 62.85(7)^{\circ}\right]$ and a relatively small pitch angle $(\theta$ $\left.2.9^{\circ}\right)$, bringing about a severely distorted $\kappa^{2}-N, O$ coordination mode. $^{22}$ In addition, the $\mathrm{O}(44)-\mathrm{C}(39)-\mathrm{N}(38)$ angle $\left[113.8(2)^{\circ}\right]$ is smaller than that reported for the free 2 pyridone $^{26}\left(121.3^{\circ}\right)$. Finally, the short $\mathrm{C}(39)-\mathrm{O}(44)$ bond

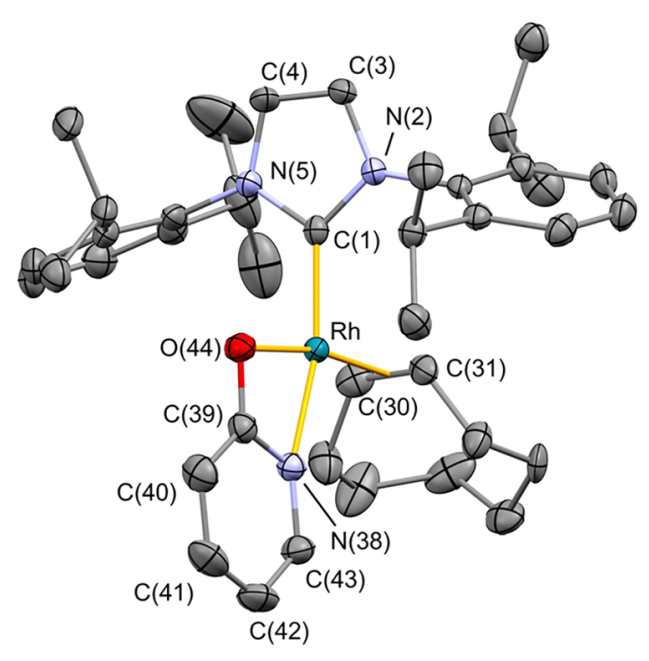

Figure 1. Solid-state crystal structure of 2 . For clarity, all hydrogen atoms are omitted. Selected bond lengths $(\AA)$ and angles (deg) are $\mathrm{N}(38)-\mathrm{Rh} 2.1536(19), \mathrm{O}(44)-\mathrm{Rh} 2.1245(16), \mathrm{C}(1)-\mathrm{Rh} 1.947(2)$, $\mathrm{Rh}-\mathrm{ct}$ 1.9655(2), C(30)-C(31) 1.393(4), C(39)-N(38) 1.366(3), $\mathrm{C}(39)-\mathrm{O}(44)$ 1.297(3), C(1)-Rh-ct 94.32(6), ct-Rh-O(44) 168.82(4), ct-Rh-N(38) 106.02(5), C(1)-Rh-O(44) 96.78(8), $\mathrm{C}(1)-\mathrm{Rh}-\mathrm{N}(38)$ 159.59(8), O(44)-Rh-N(38) 62.85(7), O(44)$\mathrm{C}(39)-\mathrm{N}(38) 113.8(2)$, ct: centroid of $\mathrm{C}(30)$ and $\mathrm{C}(31)$.

length $[1.297(3) \AA]$ suggests a major contribution of the 2pyridonato carbon-oxygen double bond tautomer.

The NMR spectra of $\mathbf{2}$ is in agreement with the solid-state structure; thus, we assume a related mononuclear squareplanar configuration also for $3-5$. The ${ }^{13} \mathrm{C}\left\{{ }^{1} \mathrm{H}\right\}$-APT NMR spectra corroborates the presence of IPr, coe, and 2heteroatom-pyridyl ligands in $\mathbf{2 - 5}$ by the appearance of three carbon-rhodium coupled doublets, with a coupling constant $J_{\mathrm{C}-\mathrm{Rh}}$ of around 60,15 , and $3 \mathrm{~Hz}$, respectively. The ${ }^{1} \mathrm{H}$ NMR spectra display the characteristic feature of a pyridinato moiety, namely, a deshielded doublet of doublets between $\delta 7.71$ and $7.19 \mathrm{ppm}$, corresponding to the $\mathrm{H}_{6-\mathrm{py}}$ proton, in addition to shielded resonances around $6 \mathrm{ppm}$, ascribed to $\mathrm{H}_{3-\mathrm{py}}$ and $\mathrm{H}_{5-\mathrm{py}}$ atoms. Also of note is the observation of only one septuplet around $3 \mathrm{ppm}$ for 2, 3, and 5 , ascribed to the four $\mathrm{CH}$-isopropyl protons of the wingtips of carbene. This fact is explained by the occurrence of a symmetry plane and a rotational process of the IPr ligand, ${ }^{27}$ whose rate slows down as a function of temperature resulting in the observation of two broad signals at $203 \mathrm{~K}$ (See Figure S1 in the Supporting Information for 2). The carbene rotation is hindered in 4 by the methyl group of the amino-pyridinato ligand. The presence of both nitrogenated ligands in 2-5 was 


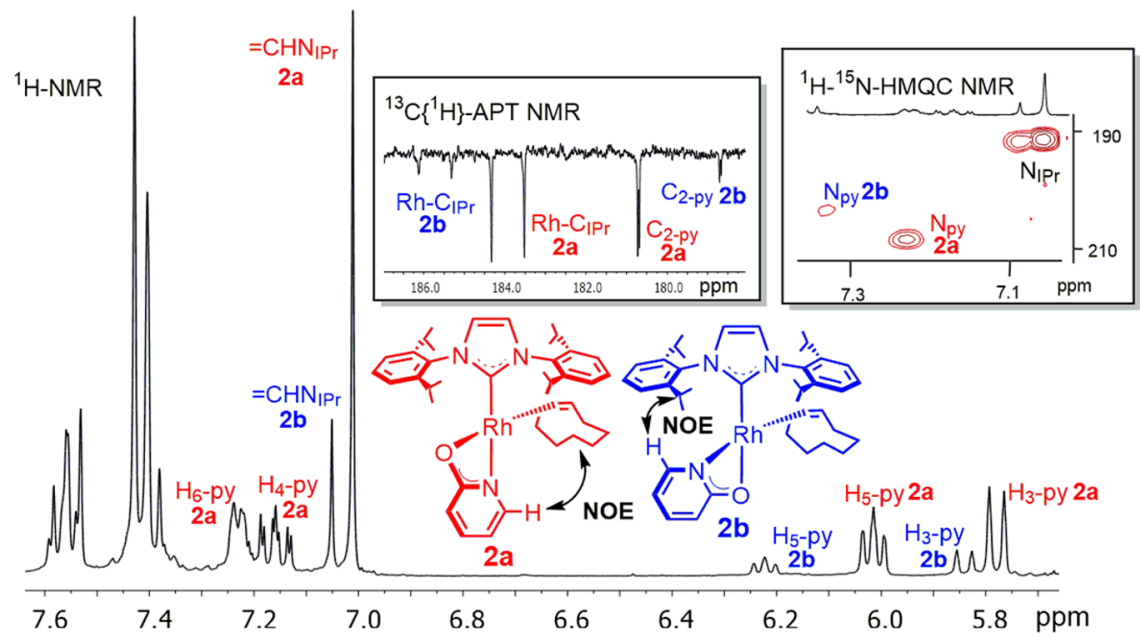

Figure 2. Selected regions of the ${ }^{1} \mathrm{H},{ }^{13} \mathrm{C}\left\{{ }^{1} \mathrm{H}\right\}$-APT and ${ }^{1} \mathrm{H}-{ }^{15} \mathrm{~N}-\mathrm{HMQC}$ NMR spectra in $\mathrm{CD}_{2} \mathrm{Cl}_{2}$ at $298 \mathrm{~K}$ for the equilibrium mixture of $\mathbf{2 a}-\mathbf{2} \mathbf{b}$.

further confirmed by ${ }^{1} \mathrm{H}-{ }^{15} \mathrm{~N}$ HMQC NMR experiments. ${ }^{15} \mathrm{~N}$ pyridyl resonances are in the expected range for metalcoordinated ligands $(\delta 198-235 \mathrm{ppm}),{ }^{15 a}$ whereas ${ }^{15} \mathrm{~N}$ signals of the IPr and amine functionalities in 3-4 appear around 192 and 105 ppm, respectively.

Interestingly, complex 2 appears as a unique species in $\mathrm{C}_{6} \mathrm{D}_{6}$

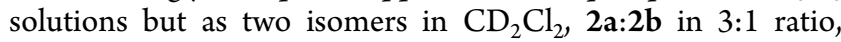
displaying opposite disposition of the chelating pyridonato ligand (Figure 2). A ${ }^{1} \mathrm{H}-{ }^{1} \mathrm{H}$ NOE NMR experiment (see Figure S15 in the Supporting Information) confirms that the major isomer (2a) presents the chelate ligand in the same disposition as that determined in the solid state, whereas the nitrogen atom is located cis to IPr in the minor isomer (2b). Both isomers are in a thermodynamic equilibrium with similar ratios in the temperature range 203-298 K, displaying fast exchange at room temperature. DFT calculations show that these isomers display a energy difference of $0.37 \mathrm{kcal} \cdot \mathrm{mol}^{-1}$ (see Figure S2 in the Supporting Information). Larger separation of 0.96 and $1.41 \mathrm{kcal} \cdot \mathrm{mol}^{-1}$ were computed for the amino- and mercapto-pyridinato derivatives, respectively, which is agreement the observation of a single isomer in solution.

Dimerization of Alkynes. The new $\mathrm{Rh}^{\mathrm{I}}$-NHC-pyridinato complexes 2-5 were evaluated as catalysts for alkyne dimerization. Phenylacetylene was initially studied as a benchmark substrate (Scheme 4, Table 1). The course of the

Scheme 4. Alkyne Dimerization Products

$$
2 \mathrm{R}=\mathrm{H} \stackrel{[\mathrm{Rh}]}{\mathrm{R}} \underset{E}{\bar{E}} \stackrel{{ }^{\mathrm{R}}}{\mathrm{R}} \underset{\mathrm{gem}}{\mathrm{R}}
$$

reaction was monitored by NMR using $2 \mathrm{~mol} \%$ of catalyst loading in $\mathrm{C}_{6} \mathrm{D}_{6}$ at $25{ }^{\circ} \mathrm{C}$. Rh-pyridonato complex 2 is extremely active and selective. Total conversion to the head-totail enyne, 1,3-diphenylbut-3-en-1-yne, was observed in the first ${ }^{1} \mathrm{H}$ NMR experiment recorded, after less than $5 \mathrm{~min}$ (entry 1). A TOF $1 / 2$ value of $16000 \mathrm{~h}^{-1}$ was calculated, which is, as far as we know, the highest value reported for alkyne dimerization at room temperature. ${ }^{11 \mathrm{i}}$ Catalytic activity remained very high after reducing catalyst loading to $0.5 \mathrm{~mol}$ $\%$, with complete phenylacetylene conversion after only $6 \mathrm{~min}$
Table 1. Catalyst Evaluation for Dimerization of Phenylacetylene $^{a}$

$\begin{array}{cccccrc}\text { entry } & \text { catalyst } & \text { mol \% } & t(\mathrm{~h}) & \text { conv }(\%) & g e m / E & \text { TOF }_{1 / 2}\left(\mathrm{~h}^{-1}\right)^{b} \\ 1 & \mathbf{2} & 2 & <0.1 & >99 & >99 & 16000 \\ 2 & \mathbf{2} & 0.5 & 0.1 & >99 & >99 & 8300 \\ 3 & \mathbf{2} & 0.1 & 3 & >99 & >99 & 11000 \\ 4 & 2 & 0.05 & 4 & 54 & >99 & 6900^{c} \\ 5 & 3 & 2 & 22 & 29 & 95 / 5 & \\ 6 & 4 & 2 & 25 & 55 & 96 / 4 & 1 \\ 7 & 5 & 2 & 5 & >99 & 54 / 46 & 11\end{array}$

${ }^{a}$ Reaction conditions: $0.5 \mathrm{~mL}$ of $\mathrm{C}_{6} \mathrm{D}_{6}, 0.5 \mathrm{mmol}$ of phenylacetylene, $25{ }^{\circ} \mathrm{C}$. ${ }^{b}$ Turnover frequency at $50 \%$ conversion. ${ }^{c}$ Calculated at $40 \%$ conversion.

of reaction (entry 2). Catalyst 2 was also efficient at $0.1 \mathrm{~mol} \%$ catalyst loading (entry 3). Further decrease of the catalyst loading to a 1:2000 catalyst:substrate ratio resulted in a $54 \%$ conversion in $4 \mathrm{~h}$, still maintaining complete selectivity for the gem-enyne product (entry 4). In contrast, amino-pyridinebased catalyst precursors 3-4 are much less efficient and selective (entries 5-6). Moreover, although Rh-mercaptopyridine catalyst $\mathbf{5}$ was able to fully transform phenylacetylene in $5 \mathrm{~h}$, it showed poor selectivity (entry 7 ).

The catalytic activity of $\mathbf{2}$ was studied for different alkynes (Table 2). Electronic modification on the aromatic ring of phenylacetylene resulted in only slight changes in catalytic activity (entries 3-4). Aliphatic alkynes were also efficiently transformed with high selectivity (entries 5-7). Catalyst 2 tolerates the presence of heteroatoms well (entries 8-10). Particularly, the hydroxy group in 3-butynol did not affect significantly the catalytic activity with regard to an ether functionality (entries 8 vs 10). It is interesting to note that this alcohol is involved for the first time in an alkyne dimerization process. ${ }^{28}$ Increasing of bulkiness in the substrate is detrimental to catalytic activity. Thus, trimethylphenylacetylene reacted very slowly but maintaining the head-to-tail selectivity (entry 11). In contrast, no regioselectivity was observed for trimethylsilylacetylene (entry 12 ), whereas $(Z)$ (1,3,5-tritert-butyl)hexa-3,5-dien-1-yne trimer was found to be the major product when tert-butylacetylene was used (entry 13). Finally, catalyst 2 was ineffective for the transformation of 2-pyridylacetylene. 
Table 2. Screening of Alkynes Catalyzed by $2^{a}$

\begin{tabular}{|c|c|c|c|c|c|}
\hline Entry & Substrate & $\mathrm{t}(\mathrm{h})$ & Conv( $\%)$ & $\mathrm{gem} / E$ & $\operatorname{TOF}_{1 / 2}\left(\mathrm{~h}^{-1}\right)^{b}$ \\
\hline 1 & & $<0.1$ & $>99$ & $>99$ & 16000 \\
\hline $2^{c}$ & & 3 & $>99$ & $>99$ & 11000 \\
\hline $3^{c}$ & & 1 & 96 & $>99$ & 12000 \\
\hline $4^{c}$ & & 2.5 & 73 & $>99$ & 17000 \\
\hline 5 & & 0.3 & $>99$ & $>99$ & 900 \\
\hline 6 & & $<0.1$ & $>99$ & $>99$ & 700 \\
\hline 7 & & $<0.1$ & $>99$ & $>99$ & 800 \\
\hline 8 & & 21 & 95 & $>99$ & 15 \\
\hline 9 & & 4 & 98 & $>99$ & 100 \\
\hline 10 & & 16 & 94 & $>99$ & 6 \\
\hline 11 & & 21 & 40 & $>99$ & - \\
\hline 12 & & 96 & $>99$ & $48 / 52$ & 2 \\
\hline 13 & & 48 & 65 & $21 / 8 / 71^{d}$ & 1 \\
\hline 14 & & 48 & - & - & - \\
\hline
\end{tabular}

${ }^{a}$ Reaction conditions: $0.5 \mathrm{~mL}$ of $\mathrm{C}_{6} \mathrm{D}_{6}, 0.5 \mathrm{mmol}$ of alkyne, 0.01 mmol of $2,25{ }^{\circ} \mathrm{C}$. ${ }^{b}$ Turnover frequency at $50 \%$ conversion. ${ }^{c} 0.1 \mathrm{~mol}$ $\%$ of $2 .^{d}(Z)-(1,3,5$-tritert-butyl)hexa-3,5-dien-1-yne trimer was also obtained.

Mechanistic Investigation. In order to shed light on the operative mechanism for the Rh-NHC-pyridinato catalyzed alkyne dimerization, low temperature reactivity studies were made. Unfortunately, catalyst $\mathbf{2}$ dimerized phenylacetylene very fast, even at $213 \mathrm{~K}$, thwarting the detection of catalytic intermediates. In view of this, reactivity studies were carried out with a less efficient catalyst or a less reactive alkyne (Scheme 5). Thus, the addition of phenylacetylene to the mercaptopyridine complex 5 at $233 \mathrm{~K}$ gave the $\pi$-phenylacetylene complex $\operatorname{Rh}\left\{\kappa^{2}-S, N-(\mathrm{Spy})\right\}\left(\eta^{2}-\mathrm{HC} \equiv \mathrm{CPh}\right)(\mathrm{IPr})$ $(6)^{11 i}$ by alkyne-coe exchange, which can be proposed as the first step of the catalytic cycle. Warming the solution led to the smooth formation of the head-to-head and head-to-tail enynes, according to the selectivity observed in the catalytic experiments (entry 7, Table 1), and a mixture of unidentified complexes. In contrast, addition of the bulky trimethylphenylacetylene to 2 afforded $\mathrm{Rh}\left\{\kappa^{2}-\mathrm{O}, \mathrm{N}-(\mathrm{Opy})\right\}\left\{\eta^{2}-\mathrm{H}_{2} \mathrm{C}=\mathrm{C}(\mathrm{Mes})\right.$ $\mathrm{C} \equiv \mathrm{C}(\mathrm{Mes})\}(\mathrm{IPr})(7)$, that results from the $\eta^{2}-\mathrm{C}=\mathrm{C}$ coordination of the enyne reaction product formed by fast dimerization of the alkyne. This uncommon coordination mode for an enyne ${ }^{29}$ is reflected in the appearance in the
Scheme 5. Reactivity of Pyridinato Complexes with Alkynes
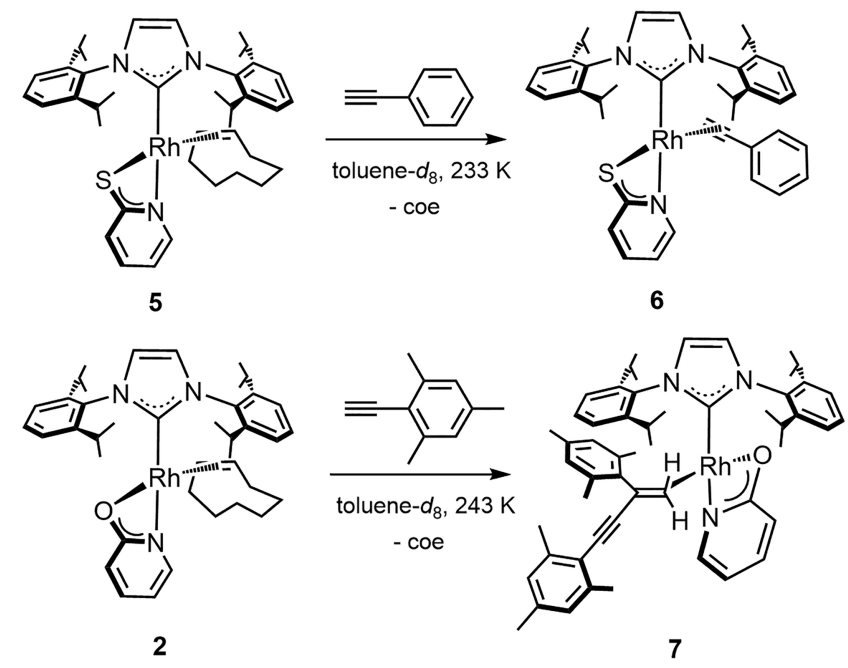

${ }^{13} \mathrm{C}\left\{{ }^{1} \mathrm{H}\right\}$-APT NMR spectrum of two doublets at $\delta 50.3$ and $41.0 \mathrm{ppm}$ with $J_{\mathrm{C}-\mathrm{Rh}}$ around $18.8 \mathrm{~Hz}$, corresponding to the coordinated olefin. Most likely, the presence of the bulky substituents in the proximity of the alkynyl moiety hinders the coordination of the triple bond.

Based on previous investigations in our group, ${ }^{11 \mathrm{i}}$ the pyridinato ligand must play a role in the deprotonation of the rather acidic terminal proton of the alkyne. Thus, addition of triflic acid to a $\mathrm{CD}_{2} \mathrm{Cl}_{2}$ solution of 2 at $223 \mathrm{~K}$ resulted in the formation of $\mathrm{Rh}\left[\kappa^{1}-\mathrm{O}-\{\mathrm{O}=\mathrm{C}(-\mathrm{CH}=\mathrm{CH}-\mathrm{CH}=\mathrm{CH}-)\right.$ $\mathrm{NH}\}]\left\{\kappa^{1}-\mathrm{O}-\left(\mathrm{CF}_{3} \mathrm{O}_{3} \mathrm{~S}\right)\right\}\left(\eta^{2}\right.$-coe $)(\mathrm{IPr})$ as a mixture of two isomers in a 1:1 ratio, tentatively assigned to $\mathbf{8 a}$ and $\mathbf{8 b}$, where the nitrogen atom of the pyridonato ligand has been protonated (Scheme 6) (see Theoretical Calculations on the Mechanism section). The ${ }^{1} \mathrm{H}-{ }^{15} \mathrm{~N}$ HMQC NMR spectrum shows two $\mathrm{NH}$ cross-peaks at $\delta 174.0$ and 170.3 which correlate with $\delta 11.73$ and $10.97 \mathrm{ppm}$ proton signals, respectively, thereby confirming the presence of pyridin$2(1 \mathrm{H})$-one ligands in both isomers. Moreover, the ${ }^{19} \mathrm{~F}$ NMR spectrum displays the typical broad signal of a coordinated triflate ligand.

Deuterium-labeling experiments using phenylacetylene- $d_{1}$ were performed with the aim of gaining information about the turnover limiting step (Scheme 7). First, the H/D kinetic isotopic effect (KIE) was measured by performing separate NMR experiments using $0.4 \mathrm{~mol} \%$ of catalyst 2 . A KIE of 1.67 \pm 0.12 was found. This relatively small value suggests that a $\mathrm{X}-\mathrm{H}$ cleavage or formation event is not likely involved in the turnover limiting step. ${ }^{30}$ Further, a catalytic test with a mixture of natural and phenylacetylene- $d_{1}$ in a 1:1 ratio resulted in a different deuteration degree of the geminal positions of the enyne. The calculated H/D ratios show the overdeuteration of the vinyl proton cis to the phenyl group $(0.37$ vs $0.63 \mathrm{H}$ ). Taking into consideration a syn addition process and no preference between natural and deuterated alkyne as the acceptor partner, this result suggests that the cleavage of the $\mathrm{C}-\mathrm{H}$ bond is 1.7 times faster than that of the $\mathrm{C}-\mathrm{D}$ bond, which is in concordance with the calculated KIE. Moreover, the ability of the pyridonato ligand to act as an efficient shuttle was analyzed. The mixture resulting from a catalytic test with phenylacetylene- $d_{1}$ and 2 in the presence of natural pyridin-2one resulted in the clean formation of gem-enyne- $d_{2}$. The lack of incorporation of protons from the heterocycle indicates that 
Scheme 6. Protonation of 2 with Triflic Acid

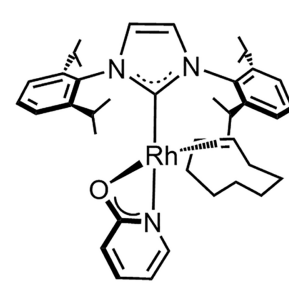

2

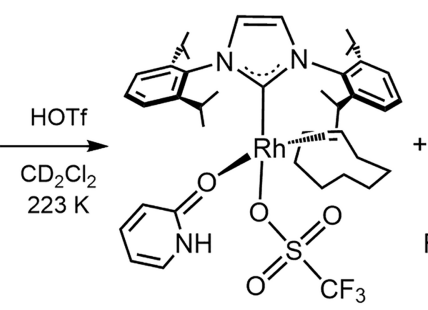

$8 a$

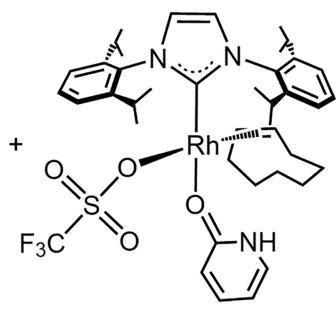

8b
Scheme 7. Deuterium Labeling Experiments

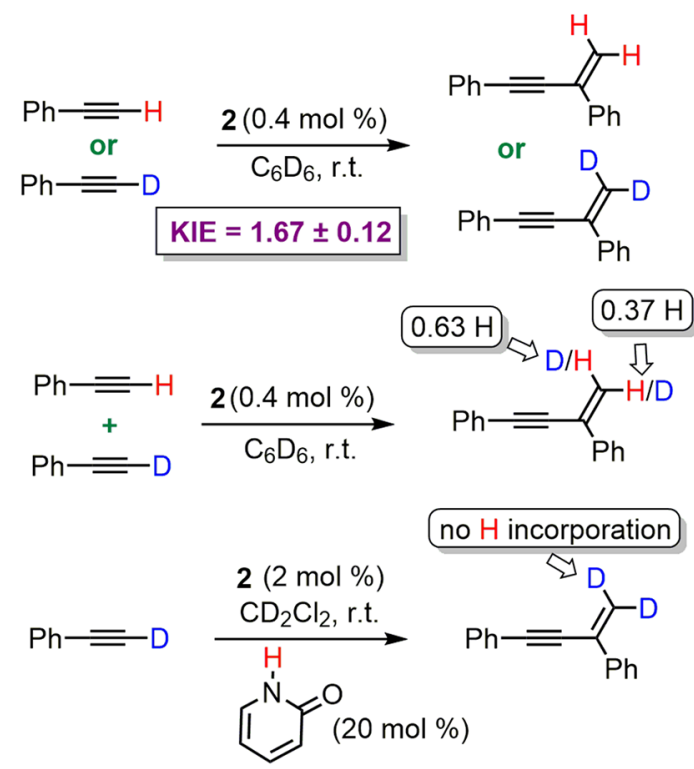

hydrogen transfer is faster than the metal-pyridone ligand coordination exchange.

Theoretical Calculations on the Mechanism. To further clarify the operating pathway leading to the observed gem-enyne selectivity, a detailed density functional theory (DFT) computational analysis on the dimerization of phenylacetylene promoted by the Rh-NHC-pyridinato complexes has been carried out. All plausible mechanistic pathways have been thoroughly examined $\left(\Delta G\right.$ in $\left.\mathrm{kcal} \cdot \mathrm{mol}^{-1}\right)$, excluding the external attack on coordinated $\pi$-alkyne and vinylidenemediated dimerization pathways as these usually do not result in gem-selectivity.

The first step considered in this study is the preactivation of catalyst 2 by phenylacetylene-coe exchange via an associative mechanism. This exergonic process $\left(-6.1 \mathrm{kcal} \cdot \mathrm{mol}^{-1}\right)$ has an energetic barrier of $13.7 \mathrm{kcal} \cdot \mathrm{mol}^{-1}$ (see Figure $\mathrm{S} 103$ in the Supporting Information). The resulting complex $\operatorname{Rh}\left\{\kappa^{2}-O, N\right.$ (Opy) $\}\left(\eta^{2}-\mathrm{HC} \equiv \mathrm{CPh}\right)(\mathrm{IPr})$ (A) can be considered as the active species, and hence, it has been selected as the energetic reference for all DFT calculations in this section.

First, we have analyzed the pathway starting by oxidative addition of the alkyne to form a $\mathrm{Rh}^{\mathrm{III}}$-hydride-alkynyl intermediate. $^{15}$ The energy profile of this cycle is shown in Figure 3. The initial step is the slippage of the $\eta^{2}-(\mathrm{C} \equiv \mathrm{C})$ alkyne bond in $\mathbf{A}$ rendering the $\eta^{2}-(\mathrm{C}-\mathrm{H})$ agostic interaction in $\mathbf{B}$. This process presents an energetic barrier characterized by TSAB of $19.9 \mathrm{kcal} \cdot \mathrm{mol}^{-1}$, and it is endergonic by $10.4 \mathrm{kcal}$. $\mathrm{mol}^{-1}$. The formation of the $\sigma$-complex $\mathbf{B}$ is essential in the cleavage of the $\mathrm{C}-\mathrm{H}$ bond. ${ }^{10 a, 13 b, \mathrm{~d}, \mathrm{f}, \mathrm{h}}$ From that point, the oxidative addition takes place by a negligible energy barrier, characterized by TSBC, leading to the $\mathrm{Rh}^{\mathrm{III}}$-hydride-alkynyl C, which presents a relative free energy of $8.3 \mathrm{kcal} \cdot \mathrm{mol}^{-1}$. The reaction continues by coordination of a second alkyne to the metal center and subsequent hydrometalation. The two possible orientations of the alkyne toward its insertion on the $\mathrm{Rh}-\mathrm{H}$ bond are characterized by the transition states TSCDg (leading to the gem product) and TSCDt (leading to the $E$ product), with free energies of 20.2 and $23.7 \mathrm{kcal} \cdot \mathrm{mol}^{-1}$, respectively. It should be noted that, although $\mathbf{D t}$ is more stable than $\mathbf{D g}$, the reaction is under kinetic control and $\mathbf{D t}$ is not accessible. The insertion of the alkyne into the $\mathrm{Rh}-\mathrm{C}$ bond has been discarded based on previous studies on similar systems. ${ }^{11 e, 15 a}$ The obtained alkynyl-alkenyl complexes D evolve to the final products via reductive elimination via TSDAg and TSDAt, showing energetic barriers of 7.4 and 12.4 $\mathrm{kcal} \cdot \mathrm{mol}^{-1}$, respectively. This mechanistic proposal presents an overall activation energy of $20.2 \mathrm{kcal} \cdot \mathrm{mol}^{-1}$ for the gem-enyne, which is preferentially obtained due to the significantly higher barrier for the $E$ product $\left(23.7 \mathrm{kcal} \cdot \mathrm{mol}^{-1}\right)$.

For the sake of comparison, a classical mechanism alternative to alkyne oxidative addition is a base-mediated nonoxidative pathway. In our case the pyridonato ligand may play this role via a concerted metalation-deprotonation (CMD) process. The energetic profile is shown in Figure 4. The reaction starts by coordination of a second alkyne to A, allowed by the hemilabile behavior of the pyridonato ligand. ${ }^{21}$ As a result, a switch to a $\left\{\kappa^{1}-N-(\mathrm{Opy})\right\}$ coordination mode of this molecule is observed. ${ }^{31}$ This process is characterized by TSAE (energetic barrier of $14.2 \mathrm{kcal} \cdot \mathrm{mol}^{-1}$ ) leading to the intermediate $\mathrm{E} \operatorname{Rh}\left\{\kappa^{1}-\mathrm{N}-(\mathrm{Opy})\right\}\left(\eta^{2}-\mathrm{HC} \equiv \mathrm{CPh}\right)_{2}(\mathrm{IPr})$, displaying a mutually trans disposition for the two $\pi$-alkyne molecules. ${ }^{32}$ Since the pyridonato ligand is now coordinated to the metal only by the nitrogen atom, free rotation about the $\mathrm{Rh}-\mathrm{N}$ bond becomes possible thus enabling the easy approach of the basic oxo group to any terminal hydrogen of the $\eta^{2}$ coordinated alkynes of $\mathbf{E}$. Therefore, the subsequent CMD step is characterized by the TSEF transition state, which has an energetic barrier of $15.9 \mathrm{kcal} \cdot \mathrm{mol}^{-1}$, leading to the intermediate F Rh $(-\mathrm{C} \equiv \mathrm{CPh})\left\{\kappa^{1}-\mathrm{N}-\{\mathrm{HOpy}\}\left(\eta^{2}-\mathrm{HC} \equiv \mathrm{CPh}\right)(\mathrm{IPr})\right.$. The possible deprotonation of the alkyne by the nitrogen atom of the pyridonato was also computed revealing a higher energetic barrier of $20.7 \mathrm{kcal} \cdot \mathrm{mol}^{-1}$ (TSEG see Figure S104 in the Supporting Information). However, the resulting pyridin-2-one intermediate $\mathbf{G}$ is almost isoenergetic to $\mathbf{F}$, in accordance to the experimental observation that $\mathbf{8}$ forms after the protonation of 2 with triflic acid.

Once the $\mathrm{Rh}^{\mathrm{I}}$-alkynyl intermediate $\mathbf{F}$ is obtained, carbometalation is available via TSFHg $\left(30.2 \mathrm{kcal} \cdot \mathrm{mol}^{-1}\right)$ or TSFHt $\left(26.5 \mathrm{kcal} \cdot \mathrm{mol}^{-1}\right)$ depending on the orientation of the alkyne 


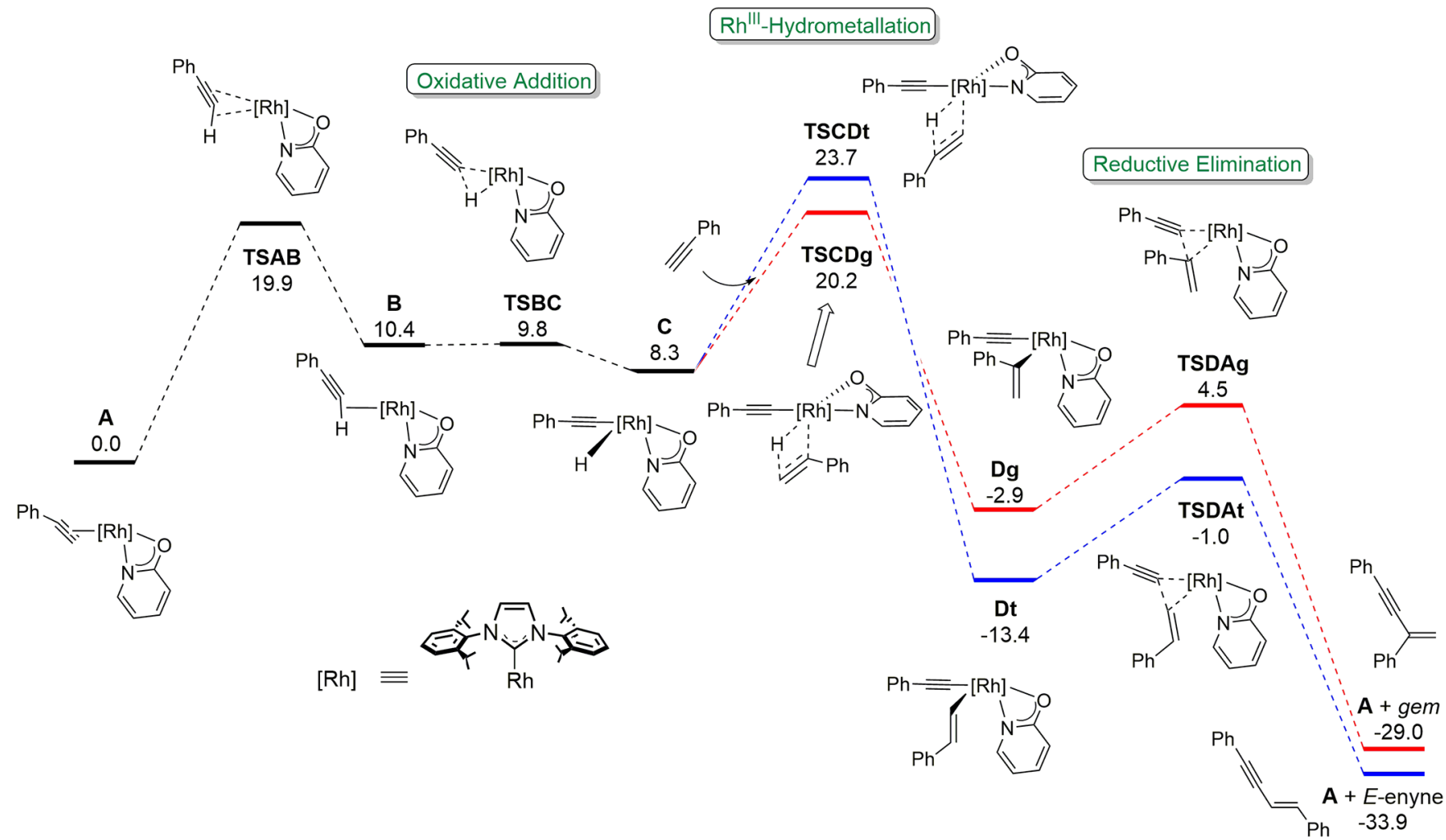

Figure 3. DFT calculations ( $\Delta G$ in $\mathrm{kcal} \cdot \mathrm{mol}^{-1}$, relative to $\mathbf{A}$ and isolated molecules) along phenylacetylene dimerization following the oxidative addition, migratory insertion, and reductive elimination steps.

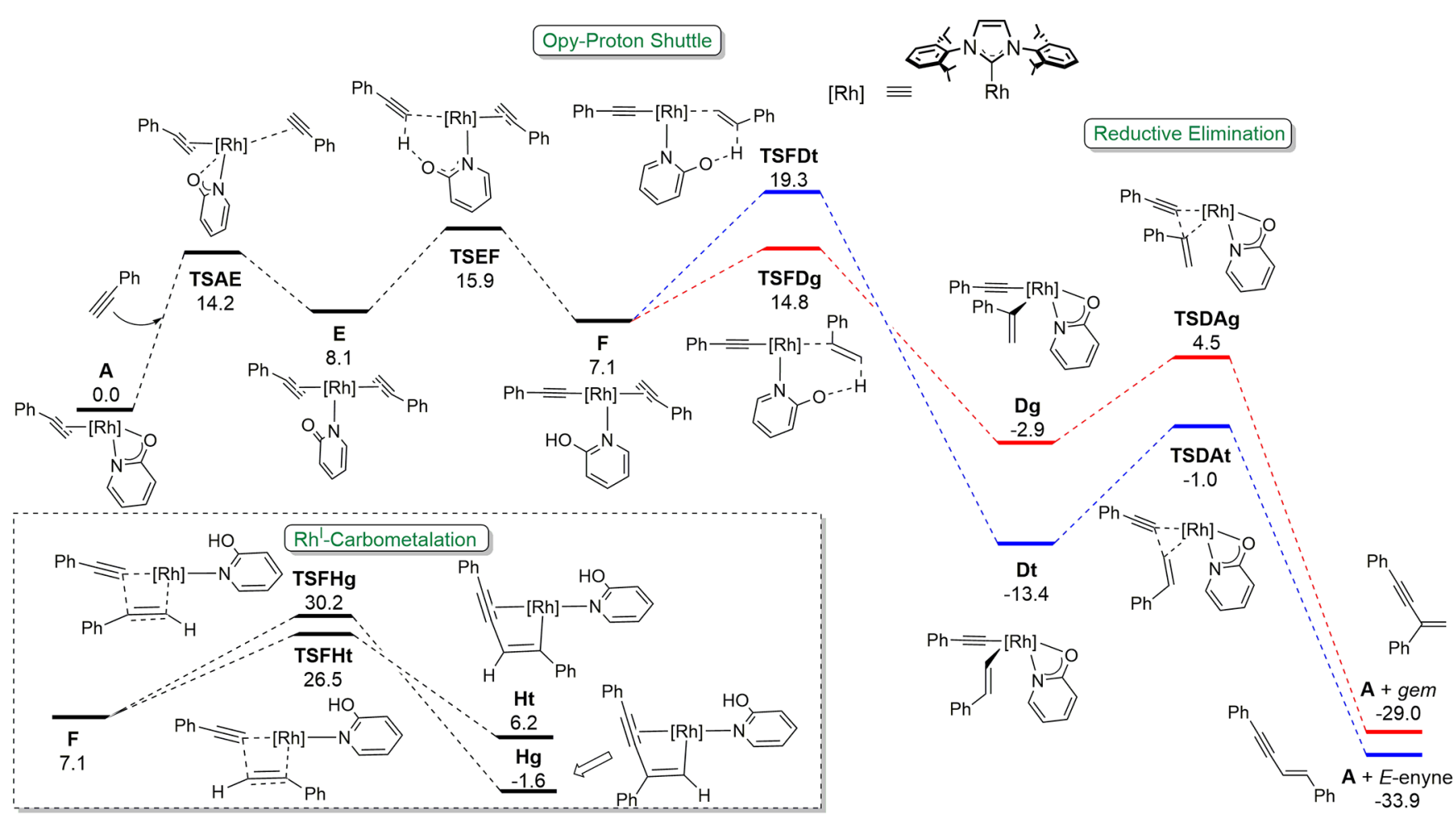

Figure 4. DFT calculations ( $\Delta G$ in $\mathrm{kcal} \cdot \mathrm{mol}^{-1}$, relative to $\mathbf{A}$ and isolated molecules) along phenylacetylene dimerization following the pyridonatomediated proton shuttle and reductive elimination steps.

(Figure 4). However, these energetic barriers are higher than that computed for the oxidative route. An alternative pathway can be envisaged starting from the $\mathrm{Rh}^{\mathrm{I}}$-alkynyl intermediate $\mathbf{F}$.
The $\kappa^{1}$-N-hydroxypyridine ligand can now act as an intramolecular Brønsted acid able to transfer the proton to the remaining $\eta^{2}$-alkyne of $\mathbf{F}$ to yield $\mathbf{D} .^{33}$ Two possibilities arise 
for this selectivity-determining step as the proton can be transferred to either the terminal or the substituted carbon atoms of phenylacetylene. Protonation of the external position via TSFDg $\left(14.8 \mathrm{kcal} \cdot \mathrm{mol}^{-1}\right)$, which ultimately leads to $\mathrm{gem}$ enynes, is much more favored than the protonation of the internal one (TSFDt, $19.3 \mathrm{kcal} \cdot \mathrm{mol}^{-1}$ ). Alternative protonation reactions by the $\kappa^{1}$-O-pyridin-2-one ligand in complex $\mathbf{G}$ are considerably more disfavored (see Figure S104 in the Supporting Information). The catalytic cycle ends via alkenyl-alkynyl reductive elimination within $\mathbf{D}$ as previously analyzed. The concurrence of the $\mathbf{E} \rightarrow \mathbf{F}$ and $\mathbf{F} \rightarrow \mathbf{D}$ steps shows a very efficient cooperative Rh-pyridonato-mediated LAPS process. Figure 4 shows that the higher energetic barrier corresponds to the CMD event (TSEF, $15.9 \mathrm{kcal} \cdot \mathrm{mol}^{-1}$ ), although those of the associative coordination of a second molecule of alkyne (TSAE, $14.2 \mathrm{kcal} \cdot \mathrm{mol}^{-1}$ ) or proton transfer (TSFDg, $14.8 \mathrm{kcal} \cdot \mathrm{mol}^{-1}$ ) are very close in energy, and thus, its contribution to the overall kinetics of the catalytic cycle might be not negligible. In order to evaluate the proposed mechanism for aliphatic alkynes, key structures were calculated considering propyne as a model system. An increment in the overall energy barrier from 15.9 to $17.7 \mathrm{kcal} \mathrm{mol}^{-1}$ is observed which is in accordance with a lower catalytic activity (see Table S3 in the Supporting Information).

As extracted from Figure 4, the regioselectivity is controlled by the proton transfer to the alkyne, determined by a difference of $4.5 \mathrm{kcal} \cdot \mathrm{mol}^{-1}$ between the energetic barriers for the gemand E-enynes. The origin of this selectivity can be explained by inspecting the $\mathrm{NBO}$ atomic charges in the intermediate $\mathbf{F}$ and the transition states TSFDg and TSFDt (Figure 5). Polar-

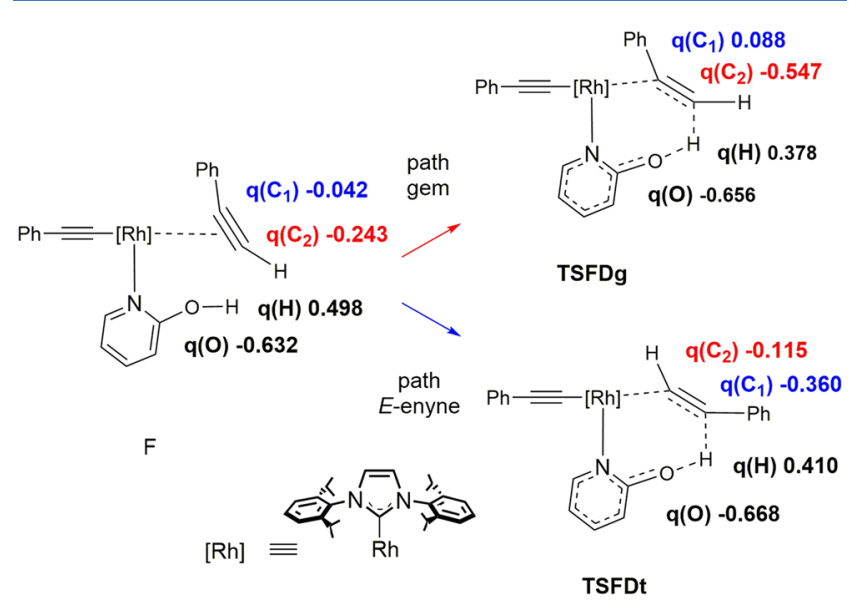

Figure 5. NBO atomic charges of atoms (in a.u.) involved in the proton transfer in structures F, TSFDg, and TSFDt.

ization of the coordinated alkyne in $\mathbf{F}$ was observed, showing a negative charge at the terminal carbon atom $(-0.243 \mathrm{e})$ larger than that at the internal position $(-0.042 \mathrm{e})$. Since the atomic charge of the hydrogen is $+0.378 \mathrm{e}$ in TSFDg and $+0.410 \mathrm{e}$ in TSFDt, the hydrogen migration can be considered formally a proton transfer, and not surprisingly, it will take place preferentially on the carbon bearing a larger negative charge, in this case the terminal carbon atom.

In order to understand the excellent catalytic performance of pyridonato complex $\mathbf{2}$ in comparison to similar aminopyridinato (3) and mercapto-pyridinato derivatives (5), the energetic barrier for the CMD step has been calculated. Deprotonation by an oxygen atom is more efficient $(15.9 \mathrm{kcal}$. $\mathrm{mol}^{-1}$ ) since the energetic barrier increases up to 22.5 and 26.5 $\mathrm{kcal} \cdot \mathrm{mol}^{-1}$ for the $\mathrm{NH}$ or $\mathrm{S}$ substituents, respectively, in agreement with the experimental results (see Figure S106 in the Supporting Information).

Mechanistic Considerations. Experimental and computational studies on the phenylacetylene dimerization catalyzed by 2 have revealed an operative metal-ligand cooperative mechanism as an alternative to the classical alkyne- $\mathrm{C}-\mathrm{H}$ oxidative-addition or base mediated nonoxidative pathways (Scheme 8). The key point of this mechanism is the role of the $\mathrm{Rh}$-pyridonato motif in the cooperative LAPS process. Initially, the hemilability of the ligand ${ }^{21}$ is essential to promote a $\kappa^{1}-N$ coordination mode which triggers the CMD step. Then, the proton is transferred selectively to the terminal position of a coordinated alkyne to finally close the cycle via a fast alkynylalkenyl reductive elimination. Indeed, the step determining the selectivity also changes. The orientation of the alkyne relative to the $\mathrm{Rh}-\mathrm{X}$ bond in the insertion step generally directs the selectivity in conventional pathways, although reductive elimination is essential in some cases. ${ }^{11 \mathrm{~h}, j}$ Thus, the difficult stereoelectronic control on $\pi$-alkyne coordination usually results in a mixture of isomers. However, the selectivity in the LAPS mechanism is directed by a protonation event. Thus, the attack to the terminal position of the alkyne is favored by $4.5 \mathrm{kcal} \cdot \mathrm{mol}^{-1}$ due to the formation of the more stable substituted carbocation intermediate, therefore enhancing specific gem-enyne formation. The combination of nitrogenoxygen atoms within a pyridinato framework seems essential, since amino or thio functionalities show a lower ability for the CMD step.

As far as the deuterium labeling experiments are concerned, the relative small $\mathrm{KIE}$ value of $1.67 \pm 0.12$ discards, in principle, a $\mathrm{C}-\mathrm{H}$ bond cleavage in the rate-determining step. However, DFT calculations have revealed that the CMD step is the one with the higher energetic barrier. A rational explanation for this, at first view paradoxical result, arises from the analysis of the CMD transition state TSEF (Figure 6). Inspection of the geometrical parameters reveals an early transition state character, as indicated by the distances $d(\mathrm{C}, \mathrm{H})$ and $d(\mathrm{O}, \mathrm{H})$ of 1.14 and $1.66 \AA$, respectively. Hence, the $\eta^{2}$ $(\mathrm{C}-\mathrm{H})$ agostic interaction component in this transition state is prevalent over the $\mathrm{C}-\mathrm{H}$ cleavage, therefore explaining its moderate effect in the KIE value. In fact, the theoretically computed KIE for this step is 1.57 , which agrees with the experimentally determined value (see Table $S 1$ in the Supporting Information).

\section{CONCLUSION}

A series of mononuclear square-planar $\operatorname{Rh}\left\{\kappa^{2}-X, N-(\mathrm{Xpy})\right\}\left(\eta^{2}-\right.$ coe)(IPr) (X = O, NH, NMe, S) BHetA complexes have been prepared. Among them, the N,O-pyridonato derivative displays an outstanding catalytic activity for gem-specific alkyne dimerization reaching $\mathrm{TOF}_{1 / 2}$ values of up to $17000 \mathrm{~h}^{-1}$ at room temperature. The proposed mechanism entails a cooperative LAPS process followed by fast alkenyl-alkynyl reductive elimination, which boosts the catalytic activity by lowering the energy barrier from 5 to $10 \mathrm{kcal} \cdot \mathrm{mol}^{-1}$ compared to $\mathrm{Rh}^{\mathrm{III}}$-hydrometalation or $\mathrm{Rh}^{\mathrm{I}}$-carbometalation conventional pathways. Hemilability of the pyridonato moiety has been revealed to be essential for an efficient CMD rate-limiting step. Moreover, the change in the selectivity-determining step from insertion to protonation is responsible for the exclusive formation of gem-enynes. These results prompt us to extend 
Scheme 8. Rh-Pyridonato Cooperative Mechanism for gem-Specific Alkyne Dimerization

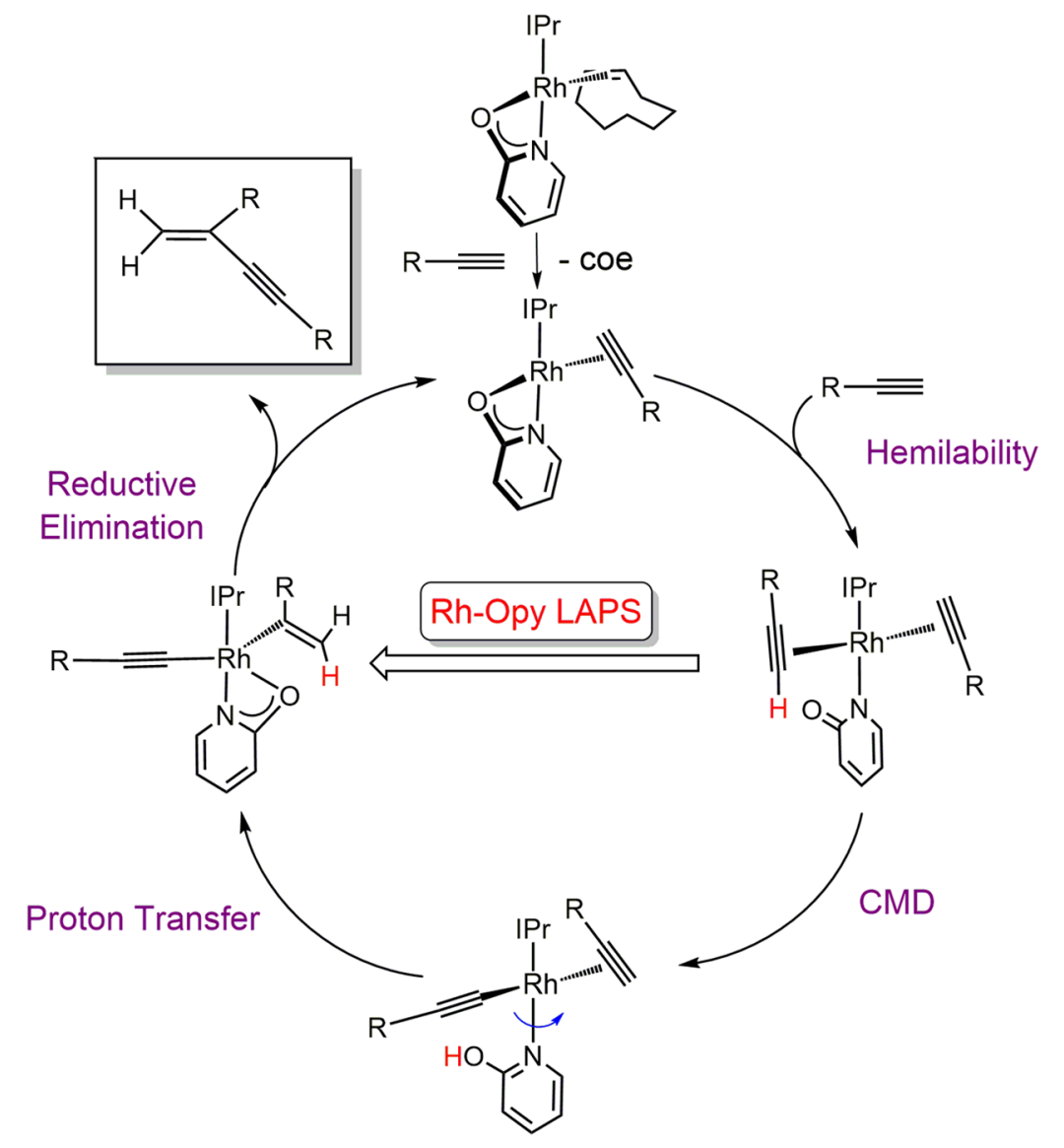

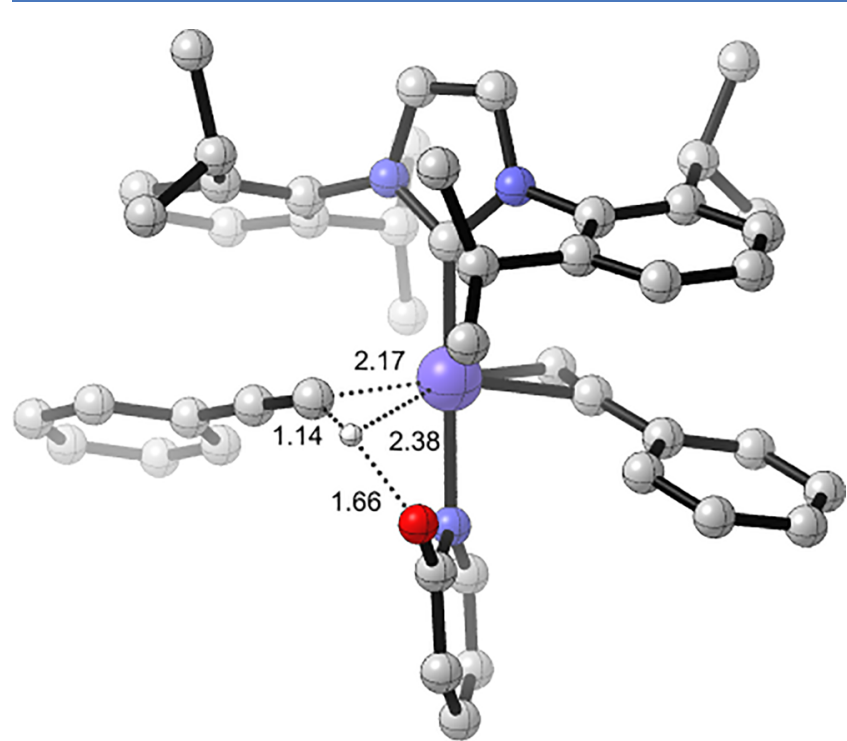

Figure 6. DFT optimized geometrical representation of TSEF. Key geometrical parameters (in $\AA$ ) are indicated.

the underlying principles described herein to related $\mathrm{C}-\mathrm{C}$ and $\mathrm{C}$-heteroatom bond forming catalytic reactions via $\mathrm{C}-\mathrm{H}$ activation.

\section{EXPERIMENTAL SECTION}

General Considerations. All reactions were performed with rigorous exclusion of air and moisture using Schlenk-tube techniques and drybox when necessary. The organometallic precursor $\left[\mathrm{Rh}(\mu-\mathrm{Cl})(\mathrm{IPr})\left(\eta^{2}-\mathrm{coe}\right)\right]_{2}$ (1) was prepared as previously described. ${ }^{34}$ Chemical shifts (expressed in parts per million) are referenced to residual solvent peaks $\left({ }^{1} \mathrm{H}\right.$ and $\left.{ }^{13} \mathrm{C}\left\{{ }^{1} \mathrm{H}\right\}\right), \mathrm{NH}_{3}\left({ }^{15} \mathrm{~N}\right)$, or $\mathrm{CFCl}_{3}\left({ }^{19} \mathrm{~F}\right)$. Coupling constants, $J$, are given in $\mathrm{Hz}$. Spectral assignments were achieved by combination of ${ }^{1} \mathrm{H}-{ }^{1} \mathrm{H}$ correlation spectroscopy (COSY), ${ }^{13} \mathrm{C}\left\{{ }^{1} \mathrm{H}\right\}$ attached proton test (APT), and ${ }^{1} \mathrm{H}-{ }^{13} \mathrm{C}$ heteronuclear single quantum correlation/heteronuclear multiple bond correlation (HSQC/HMBC) experiments.

Preparation of $\operatorname{Rh}\left\{\kappa^{2}-O, N-(O p y)\right\}\left(\eta^{2}-\right.$ coe)(IPr) $(2 a, b)$. A mixture of 2-hydroxypyridine $\left(49 \mathrm{mg}, 0.52 \mathrm{mmol}\right.$ ) and ${ }^{t} \mathrm{BuOK}$ $(58 \mathrm{mg}, 0.52 \mathrm{mmol})$ in $5 \mathrm{~mL}$ of THF was stirred for $30 \mathrm{~min}$ at r.t. Then, a solution of dinuclear complex 1 (300 mg, 0.24 $\mathrm{mmol}$ ) in $10 \mathrm{~mL}$ of THF was added, and the resulting mixture was stirred for an additional $1 \mathrm{~h}$ at r.t. After removing the solvent in vacuo, the residue was dissolved in toluene $(10 \mathrm{~mL})$ and was filtered through celite. Then, the filtrate was evaporated to dryness. The addition of hexane at $-40{ }^{\circ} \mathrm{C}$ induced the precipitation of a yellow solid, which was washed with cold hexane $(3 \times 2 \mathrm{~mL})$ and dried in vacuo. Yield: 236 mg (72\%). Satisfactory elemental analysis could not be obtained. HRMS $\left(\right.$ ESI $\left.^{+}\right): m / z$ calc for $\mathrm{C}_{40} \mathrm{H}_{54} \mathrm{~N}_{3} \mathrm{RhO}\left(\mathrm{M}^{+}-\right.$ coe - H) $583.2180 \exp 583.2173$. IR ( $\mathrm{cm}^{-1}$, ATR): 1598 $\nu\left(\mathrm{OCN}_{\text {sym }}\right), 1471 \nu\left(\mathrm{OCN}_{\text {asym }}\right)$. NMR data evidenced the presence of two isomers $\mathbf{2 a}$ and $\mathbf{2 b}$ (80:20), in equilibrium. Data for complex 2a: ${ }^{1} \mathrm{H}$ NMR (500.1 MHz, $\left.\mathrm{CD}_{2} \mathrm{Cl}_{2}, 298 \mathrm{~K}\right)$ : $\delta 7.51\left(\mathrm{t}, J_{\mathrm{H}-\mathrm{H}}=8.0,2 \mathrm{H}, \mathrm{H}_{\mathrm{p}-\mathrm{Ph}-\mathrm{IPr}}\right), 7.38\left(\mathrm{~d}, J_{\mathrm{H}-\mathrm{H}}=8.0,4 \mathrm{H}\right.$, $\mathrm{H}_{\mathrm{m}-\mathrm{Ph}-\mathrm{IPr}}$ ), 7.19 (dd, $\left.J_{\mathrm{H}-\mathrm{H}}=5.2,1.9,1 \mathrm{H}, \mathrm{H}_{6-\mathrm{py}}\right), 7.11$ (ddd, $\left.J_{\mathrm{H}-\mathrm{H}}=8.6,6.9,1.9,1 \mathrm{H}, \mathrm{H}_{4-\mathrm{py}}\right), 6.97\left(\mathrm{~s}, 2 \mathrm{H},=\mathrm{CHN}_{\mathrm{IPr}}\right), 5.97$ 
$\left(\mathrm{ddd}, J_{\mathrm{H}-\mathrm{H}}=6.9,5.2,1.1,1 \mathrm{H}, \mathrm{H}_{5-\mathrm{py}}\right), 5.74\left(\mathrm{dd}, J_{\mathrm{H}-\mathrm{H}}=8.6,1.1\right.$, $\left.1 \mathrm{H}, \mathrm{H}_{3-\mathrm{py}}\right), 2.98\left(\mathrm{sept}, J_{\mathrm{H}-\mathrm{H}}=6.8,4 \mathrm{H}, \mathrm{CHMe}_{\mathrm{IPr}}\right), 2.57(\mathrm{~m}, 2 \mathrm{H}$, $\left.=\mathrm{CH}_{\text {coe }}\right), 1.6-1.0\left(12 \mathrm{H}, \mathrm{CH}_{2-\text { coe }}\right), 1.42$ and 1.12 (both $\mathrm{d}$, $\left.J_{\mathrm{H}-\mathrm{H}}=6.8,24 \mathrm{H}, \mathrm{CHMe} \underline{\mathrm{IPr}}_{\mathrm{Ir}}\right) .{ }^{13} \mathrm{C}\left\{{ }^{1} \mathrm{H}\right\}$-APT NMR $(125.8 \mathrm{MHz}$, $\left.\mathrm{CD}_{2} \mathrm{Cl}_{2}, 298 \mathrm{~K}\right): \delta 184.5\left(\mathrm{~d}, J_{\mathrm{C}-\mathrm{Rh}}=61.1, \mathrm{Rh}-\mathrm{C}_{\mathrm{IPr}}\right), 181.3(\mathrm{~d}$, $\left.J_{\mathrm{C}-\mathrm{Rh}}=3.0, \mathrm{C}_{2-\mathrm{py}}\right), 147.5\left(\mathrm{~s}, \mathrm{C}_{\mathrm{q}-\mathrm{IPr}}\right), 144.7\left(\mathrm{~s}, \mathrm{C}_{6-\mathrm{py}}\right), 138.9(\mathrm{~s}$, $\left.\mathrm{C}_{4-\mathrm{py}}\right), 137.4\left(\mathrm{~s}, \mathrm{C}_{\mathrm{q}} \mathrm{N}\right), 129.9\left(\mathrm{~s}, \mathrm{CH}_{\mathrm{p}-\mathrm{Ph}-\mathrm{IPr}}\right), 124.9\left(\mathrm{~d}, \mathrm{~J}_{\mathrm{C}-\mathrm{Rh}}=\right.$ $\left.1.2,=\mathrm{CHN}_{\mathrm{IPr}}\right), 124.1\left(\mathrm{~s}, \mathrm{CH}_{\mathrm{m}-\mathrm{Ph}-\mathrm{IPr}}\right), 110.7\left(\mathrm{~d}, J_{\mathrm{C}-\mathrm{Rh}}=1.2\right.$, $\mathrm{C}_{3-\mathrm{py}}$ ), 108.4 (s, $\left.\mathrm{C}_{5-\mathrm{py}}\right), 57.8\left(\mathrm{~d}, J_{\mathrm{C}-\mathrm{Rh}}=16.0,=\mathrm{CH}_{\text {coe }}\right.$ ), 30.4, 30.3, and 27.8 (both s, $\mathrm{CH}_{2 \text {-coe }}$ ), 29.3 (s, $\underline{\mathrm{C} H M e} \mathrm{IPr}_{\mathrm{IP}}$ ), 26.6 and 23.2 (both s, CHMe ${ }_{\text {IPr }}$ ). ${ }^{1} \mathrm{H}-{ }^{15} \mathrm{~N}$ HMQC NMR (50.7 MHz, $\left.\mathrm{CD}_{2} \mathrm{Cl}_{2}, 298 \mathrm{~K}\right): \delta 207.8\left(\mathrm{~N}_{\mathrm{py}}\right), 191.8\left(\mathrm{~N}_{\mathrm{IPr}}\right)$. Data for complex 2b: ${ }^{1} \mathrm{H}$ NMR $\left(500.1 \mathrm{MHz}, \mathrm{CD}_{2} \mathrm{Cl}_{2}, 298 \mathrm{~K}\right): \delta 7.52\left(\mathrm{t}, J_{\mathrm{H}-\mathrm{H}}=\right.$ 8.0, 2H, $\mathrm{H}_{\mathrm{p}-\mathrm{Ph}-\mathrm{IPr}}$ ), 7.38 (d, $\left.\mathrm{J}_{\mathrm{H}-\mathrm{H}}=8.0,4 \mathrm{H}, \mathrm{H}_{\mathrm{m}-\mathrm{Ph}-\mathrm{IPr}}\right), 7.32(\mathrm{dd}$, $\left.J_{\mathrm{H}-\mathrm{H}}=5.2,1.9,1 \mathrm{H}, \mathrm{H}_{6-\mathrm{py}}\right), 7.17\left(\mathrm{ddd}, J_{\mathrm{H}-\mathrm{H}}=8.7,6.9,1.9,1 \mathrm{H}\right.$, $\left.\mathrm{H}_{4-\mathrm{py}}\right), 7.01\left(\mathrm{~s}, 2 \mathrm{H},=\mathrm{CHN}_{\mathrm{IPr}}\right), 6.18\left(\mathrm{ddd}, J_{\mathrm{H}-\mathrm{H}}=6.9,5.2,1.1\right.$, $\left.1 \mathrm{H}, \mathrm{H}_{5-\mathrm{py}}\right), 5.80\left(\mathrm{dd}, J_{\mathrm{H}-\mathrm{H}}=8.7,1.1,1 \mathrm{H}, \mathrm{H}_{3-\mathrm{py}}\right), 2.84(\mathrm{~m}, 6 \mathrm{H}$, $\mathrm{CHMe}_{\mathrm{IPr}}$ and $\left.=\mathrm{CH}_{\text {coe }}\right), 1.6-1.0\left(12 \mathrm{H}, \mathrm{CH}_{2-\text { coe }}\right), 1.18$ and 1.13 (both $\mathrm{d}, J_{\mathrm{H}-\mathrm{H}}=6.8,24 \mathrm{H}, \mathrm{CHMe} \underline{\mathrm{IPr}}_{\mathrm{r}}$ ). ${ }^{13} \mathrm{C}\left\{{ }^{1} \mathrm{H}\right\}$-APT NMR $\left(125.8 \mathrm{MHz}, \mathrm{CD}_{2} \mathrm{Cl}_{2}, 298 \mathrm{~K}\right): \delta 186.2\left(\mathrm{~d}, J_{\mathrm{C}-\mathrm{Rh}}=61.7, \mathrm{Rh}-\right.$ $\left.\mathrm{C}_{\mathrm{IPr}}\right), 179.2\left(\mathrm{~d}, J_{\mathrm{C}-\mathrm{Rh}}=3.0, \mathrm{C}_{2-\mathrm{py}}\right), 147.1\left(\mathrm{~s}, \mathrm{C}_{\mathrm{q}-\mathrm{IPr}}\right), 144.8(\mathrm{~d}$, $\left.J_{\mathrm{C}-\mathrm{Rh}}=1.8, \mathrm{C}_{6-\mathrm{py}}\right), 138.5\left(\mathrm{~s}, \mathrm{C}_{4-\mathrm{py}}\right), 137.4\left(\mathrm{~s}, \mathrm{C}_{\mathrm{q}} \mathrm{N}\right), 130.1(\mathrm{~s}$, $\left.\mathrm{CH}_{\mathrm{p}-\mathrm{Ph}-\mathrm{IPr}}\right), 125.3\left(\mathrm{~s}, \mathrm{~d}, J_{\mathrm{C}-\mathrm{Rh}}=1.2,=\mathrm{CHN}_{\mathrm{IPr}}\right), 124.3(\mathrm{~s}$, $\left.\mathrm{CH}_{\mathrm{m}-\mathrm{Ph}-\mathrm{IPr}}\right), 112.3\left(\mathrm{~s}, \mathrm{C}_{3-\mathrm{py}}\right), 108.2\left(\mathrm{~d}, J_{\mathrm{C}-\mathrm{Rh}}=1.5, \mathrm{C}_{5-\mathrm{py}}\right), 62.1$ $\left(\mathrm{d}, J_{\mathrm{C}-\mathrm{Rh}}=15.5,=\mathrm{CH}_{\mathrm{coe}}\right), 30.0$ and $28.2\left(\right.$ both $\mathrm{d}, J_{\mathrm{C}-\mathrm{Rh}}=1.7$, $\mathrm{CH}_{2 \text {-coe }}$ ), 29.3 (s, $\left.\underline{\mathrm{C}} \mathrm{HMe}_{\mathrm{IPr}}\right), 27.1\left(\mathrm{~s}, \mathrm{CH}_{2-\text { coe }}\right), 26.6$ and 22.7 (both s, CHMe $\left.\underline{\mathrm{IPr}}_{\mathrm{rr}}\right) .{ }^{1} \mathrm{H}-{ }^{15} \mathrm{~N}$ HMQC NMR $(50.7 \mathrm{MHz}$, $\left.\mathrm{CD}_{2} \mathrm{Cl}_{2}, 298 \mathrm{~K}\right): \delta 203.0\left(\mathrm{~N}_{\mathrm{py}}\right), 192.2\left(\mathrm{~N}_{\mathrm{IPr}}\right)$.

Preparation of $\mathbf{R h}\left\{\boldsymbol{\kappa}^{2}-\mathrm{N}, \mathrm{N}-(\mathrm{NHpy})\right\}\left(\boldsymbol{\eta}^{2}\right.$-coe)(IPr) (3). This compound was prepared as described for 2 starting from 2aminopyridine (30 mg, $0.32 \mathrm{mmol}$ ), ${ }^{t} \mathrm{BuOK}$ (37 mg, 0.33 $\mathrm{mmol}$ ), and 1 ( $200 \mathrm{mg}, 0.16 \mathrm{mmol})$. Yellow solid. Yield: 130 $\mathrm{mg}(59 \%)$. Satisfactory elemental analysis could not be obtained. HRMS $\left(\mathrm{ESI}^{+}\right): \mathrm{m} / z$ calcd for $\mathrm{RhC}_{40} \mathrm{H}_{55} \mathrm{~N}_{4}\left(\mathrm{M}^{+}-\right.$ coe - H) 583.2314 exp 583.2303. IR ( $\mathrm{cm}^{-1}$, ATR): 1595 $\nu\left(\mathrm{NCN}_{\text {sym }}\right), 1447 \nu\left(\mathrm{NCN}_{\text {asym }}\right) .{ }^{1} \mathrm{H}$ NMR $\left(400.2 \mathrm{MHz}, \mathrm{C}_{6} \mathrm{D}_{6}\right.$, $298 \mathrm{~K}): \delta 7.37\left(\mathrm{dd}, J_{\mathrm{H}-\mathrm{H}}=5.5,1.8,1 \mathrm{H}, \mathrm{H}_{6-\mathrm{py}}\right), 7.29\left(\mathrm{t}, J_{\mathrm{H}-\mathrm{H}}=\right.$ 7.2, $\left.2 \mathrm{H}, \mathrm{H}_{\mathrm{p}-\mathrm{Ph}-\mathrm{IPr}}\right), 7.18\left(\mathrm{~d}, \mathrm{~J}_{\mathrm{H}-\mathrm{H}}=7.2,4 \mathrm{H}, \mathrm{H}_{\mathrm{m}-\mathrm{Ph}-\mathrm{IPr}}\right), 6.76$ (ddd, $\left.J_{\mathrm{H}-\mathrm{H}}=8.7,6.9,1.8,1 \mathrm{H}, \mathrm{H}_{4-\mathrm{py}}\right), 6.47\left(\mathrm{~s}, 2 \mathrm{H},=\mathrm{CHN}_{\mathrm{IPr}}\right)$, $5.63\left(\mathrm{ddd}, J_{\mathrm{H}-\mathrm{H}}=6.9,5.5,1.0,1 \mathrm{H}, \mathrm{H}_{5-\mathrm{py}}\right), 5.51\left(\mathrm{dd}, J_{\mathrm{H}-\mathrm{H}}=\right.$ 8.7, 1.0, $1 \mathrm{H}, \mathrm{H}_{3-\mathrm{py}}$ ), 3.67 (d, $\left.J_{\mathrm{H}-\mathrm{Rh}}=6.6,1 \mathrm{H}, \mathrm{NH}\right), 3.11$ (sept, $\left.J_{\mathrm{H}-\mathrm{H}}=6.8,4 \mathrm{H}, \underline{\mathrm{C}} \underline{\mathrm{HMe}} \mathrm{IPr}_{\mathrm{Ir}}\right), 2.73\left(\mathrm{~m}, 2 \mathrm{H},=\mathrm{CH}_{\mathrm{coe}}\right), 2.0-1.2(\mathrm{~m}$, $12 \mathrm{H}, \mathrm{CH}_{2-\text { coe }}$ ), 1.50 and 1.04 (both $\mathrm{d}, J_{\mathrm{H}-\mathrm{H}}=6.8,24 \mathrm{H}$, $\left.\mathrm{CHMe}_{\text {IPr }}\right) .{ }^{13} \mathrm{C}\left\{{ }^{1} \mathrm{H}\right\}$-APT NMR $\left(100 \mathrm{MHz}, \mathrm{C}_{6} \mathrm{D}_{6}, 298 \mathrm{~K}\right): \delta$ $187.6\left(\mathrm{~d}, J_{\mathrm{C}-\mathrm{Rh}}=63.8, \mathrm{Rh}-\mathrm{C}_{\mathrm{IPr}}\right), 177.8\left(\mathrm{~d}, J_{\mathrm{C}-\mathrm{Rh}}=4.2, \mathrm{C}_{2-\mathrm{py}}\right)$, $146.6\left(\mathrm{~s}, \mathrm{C}_{\mathrm{q}-\mathrm{IPr}}\right), 145.9\left(\mathrm{~s}, \mathrm{C}_{6-\mathrm{py}}\right), 137.8\left(\mathrm{~s}, \mathrm{C}_{\mathrm{q}} \mathrm{N}\right), 137.0(\mathrm{~s}$, $\mathrm{C}_{4-\mathrm{py}}$ ), 129.6 (s, $\mathrm{CH}_{\mathrm{p}-\mathrm{Ph}-\mathrm{IPr}}$ ), 123.9 (s, $\mathrm{CH}_{\mathrm{m}-\mathrm{Ph}-\mathrm{IPr}}$ ), 123.9 (= $\left.\mathrm{CHN}_{\mathrm{IPr}}\right), 107.5\left(\mathrm{~d}, J_{\mathrm{C}-\mathrm{Rh}}=1.3, \mathrm{C}_{3-\mathrm{py}}\right), 104.7\left(\mathrm{~s}, \mathrm{C}_{5-\mathrm{py}}\right), 59.7(\mathrm{~d}$, $\left.J_{\mathrm{C}-\mathrm{Rh}}=14.5,=\mathrm{CH}_{\text {coe }}\right), 30.6\left(\mathrm{~d}, J_{\mathrm{C}-\mathrm{Rh}}=1.0, \mathrm{CH}_{2-\mathrm{coe}}\right), 29.9(\mathrm{~d}$, $\left.J_{\mathrm{C}-\mathrm{Rh}}=1.7, \mathrm{CH}_{2-\text { coe }}\right), 27.1\left(\mathrm{~s}, \mathrm{CH}_{2-\text { coe }}\right), 29.1$ (s, $\left.\underline{\mathrm{C}} \mathrm{HMe}_{\mathrm{IPr}}\right)$, 26.2 and 23.0 (both s, $\mathrm{CHMe} \mathrm{IPr}_{\mathrm{IPr}}$ ). ${ }^{1} \mathrm{H}-{ }^{15} \mathrm{~N}$ HMQC NMR $\left(40.5 \mathrm{MHz}, \mathrm{C}_{6} \mathrm{D}_{6}, 298 \mathrm{~K}\right): \delta 198.8\left(\mathrm{~N}_{\mathrm{py}}\right), 190.8\left(\mathrm{~N}_{\mathrm{IPr}}\right), 105.0$ $(\mathrm{NH})$.

Preparation of $\mathrm{Rh}\left[\kappa^{2}-N, N-\{\mathrm{N}(\mathrm{Me}) \mathrm{py}\}\right]\left(\eta^{2}-\mathrm{coe}\right)(\mathrm{IPr})$ (4). This compound was prepared as described for 2 starting from $\mathrm{N}$-methyl-2-aminopyridine (29 mg, $0.26 \mathrm{mmol}),{ }^{t} \mathrm{BuOK}(29$ $\mathrm{mg}, 0.26 \mathrm{mmol})$, and $1(150 \mathrm{mg}, 0.12 \mathrm{mmol})$. Yellow solid. Yield: $102 \mathrm{mg}$ (61\%). Anal. calcd for $\mathrm{C}_{41} \mathrm{H}_{57} \mathrm{~N}_{4} \mathrm{Rh}$ : C, 69.47; $\mathrm{H}, 8.11$; N, 7.90. Found: C, 69.35; H, 8.06; N, 7.53. IR ( $\mathrm{cm}^{-1}$, ATR): $1594 \nu\left(\mathrm{NCN}_{\text {sym }}\right), 1487 \nu\left(\mathrm{NCN}_{\text {asym }}\right) .{ }^{1} \mathrm{H}$ NMR (300.1 $\left.\mathrm{MHz}, \mathrm{C}_{6} \mathrm{D}_{6}, 298 \mathrm{~K}\right): \delta 7.38\left(\mathrm{dd}, J_{\mathrm{H}-\mathrm{H}}=5.4,1.8,1 \mathrm{H}, \mathrm{H}_{6-\mathrm{py}}\right)$, 7.4-7.1 (m, 6H, $\mathrm{H}_{\mathrm{Ph}-\mathrm{IPr}}$ ), 7.02 (ddd, $J_{\mathrm{H}-\mathrm{H}}=8.8,6.9,1.8,1 \mathrm{H}$, $\left.\mathrm{H}_{4-\mathrm{py}}\right), 6.48\left(\mathrm{~s}, 2 \mathrm{H},=\mathrm{CHN}_{\mathrm{IPr}}\right), 5.7-5.6\left(\mathrm{~m}, 2 \mathrm{H}, \mathrm{H}_{5-\mathrm{py}}\right.$ and
$\mathrm{H}_{3-\mathrm{py}}$ ), 3.99 and 2.05 (both sept, $J_{\mathrm{H}-\mathrm{H}}=6.7,4 \mathrm{H}, \mathrm{CHMe}_{\mathrm{IPr}}$ ), $2.73(\mathrm{~s}, 3 \mathrm{H}, \mathrm{NMe}), 2.66\left(\mathrm{~m}, 2 \mathrm{H},=\mathrm{CH}_{\text {coe }}\right), 1.8-1.0(\mathrm{~m}, 12 \mathrm{H}$, $\mathrm{CH}_{2-\text { coe }}$ ), 1.53, 1.29, 1.16, and 0.98 (all d, $J_{\mathrm{H}-\mathrm{H}}=6.7,24 \mathrm{H}$, $\left.\mathrm{CHMe}_{\text {IPr }}\right) .{ }^{13} \mathrm{C}\left\{{ }^{1} \mathrm{H}\right\}$-APT NMR $\left(75.5 \mathrm{MHz}, \mathrm{C}_{6} \mathrm{D}_{6}, 298 \mathrm{~K}\right): \delta$ $192.3\left(\mathrm{~d}, J_{\mathrm{C}-\mathrm{Rh}}=60.0, \mathrm{Rh}-\mathrm{C}_{\mathrm{IPr}}\right), 177.1\left(\mathrm{~d}, J_{\mathrm{C}-\mathrm{Rh}}=4.0, \mathrm{C}_{2-\mathrm{py}}\right)$, 147.5 and 146.4 (both s, $\mathrm{C}_{\mathrm{q}-\mathrm{IPr}}$ ), 145.9 (s, $\mathrm{C}_{6-\mathrm{py}}$ ), 137.7 (s, $\mathrm{C}_{\mathrm{q}} \mathrm{N}$ ), 137.6 (s, $\left.\mathrm{C}_{4-\mathrm{py}}\right), 129.7,124.8$, and 123.6 (all s, $\mathrm{CH}_{\mathrm{Ph}-\mathrm{IPr}}$ ), $124.5\left(\mathrm{~d}, J_{\mathrm{C}-\mathrm{Rh}}=1.3,=\mathrm{CHN}_{\mathrm{IPr}}\right), 104.1\left(\mathrm{~s}, \mathrm{C}_{5-\mathrm{py}}\right), 100.7(\mathrm{~s}$, $\left.\mathrm{C}_{3-\mathrm{py}}\right), 57.9\left(\mathrm{~d}, J_{\mathrm{C}-\mathrm{Rh}}=14.6,=\mathrm{CH}_{\text {coe }}\right), 36.0\left(\mathrm{~d}, J_{\mathrm{C}-\mathrm{Rh}}=3.5, \mathrm{~N}-\right.$ $\mathrm{Me}$ ), 30.6 and 29.7 (both $\mathrm{d}, J_{\mathrm{C}-\mathrm{Rh}}=1.0, \mathrm{CH}_{2-\text { coe }}$ ), 29.0 and 28.8 (both s, $\underline{\mathrm{C}} \mathrm{HMe}_{\mathrm{IPr}}$ ), 27.2 (s, $\mathrm{CH}_{2-\text { coe }}$ ), 26.9, 26.0, 23.3, and

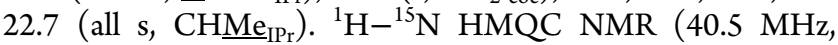
$\left.\mathrm{C}_{6} \mathrm{D}_{6}, 298 \mathrm{~K}\right): \delta 200.1\left(\mathrm{~N}_{\mathrm{py}}\right), 191.7\left(\mathrm{~N}_{\mathrm{IPr}}\right), 106.0(\mathrm{NMe})$.

Preparation of $\operatorname{Rh}\left\{\boldsymbol{\kappa}^{2}-\mathrm{S}, \boldsymbol{N}-(\mathrm{Spy})\right\}\left(\boldsymbol{\eta}^{2}-\mathrm{Coe}\right)(\mathrm{IPr})$ (5). This compound was prepared as described for 2 starting from 2mercaptopyridine $(38 \mathrm{mg}, 0.35 \mathrm{mmol}),{ }^{t} \mathrm{BuOK}$ (39 mg, 0.35 $\mathrm{mmol})$, and $\mathbf{1}(200 \mathrm{mg}, 0.16 \mathrm{mmol})$. Orange solid. Yield: 123 mg (55\%). Anal. calcd for $\mathrm{C}_{40} \mathrm{H}_{54} \mathrm{~N}_{3} \mathrm{SRh}$ : C, 67.49; $\mathrm{H}, 7.65 ; \mathrm{N}$, 5.90; S, 4.50. Found: C, 67.19; H, 7.44; N, 6.22; S, 4.45. IR ( $\left.\mathrm{cm}^{-1}, \mathrm{ATR}\right): 1579$ and $1444 \nu(\mathrm{SCN}) .{ }^{1} \mathrm{H}$ NMR $(400.2 \mathrm{MHz}$, $\left.\mathrm{C}_{6} \mathrm{D}_{6}, 298 \mathrm{~K}\right): \delta 7.71\left(\mathrm{dd}, J_{\mathrm{H}-\mathrm{H}}=5.5,1.7,1 \mathrm{H}, \mathrm{H}_{6-\mathrm{py}}\right), 7.3-7.2$ $\left(\mathrm{m}, 6 \mathrm{H}, \mathrm{H}_{\mathrm{Ph}-\mathrm{IPr}}\right), 6.56\left(\mathrm{dd}, J_{\mathrm{H}-\mathrm{H}}=8.1,1.4,1 \mathrm{H}, \mathrm{H}_{3-\mathrm{py}}\right), 6.54(\mathrm{~s}$, $\left.2 \mathrm{H},=\mathrm{CHN}_{\mathrm{IPr}}\right), 6.47\left(\mathrm{ddd}, J_{\mathrm{H}-\mathrm{H}}=8.1,7.2,1.7,1 \mathrm{H}, \mathrm{H}_{4-\mathrm{py}}\right), 5.85$ $\left(\mathrm{ddd}, J_{\mathrm{H}-\mathrm{H}}=7.2,5.5,1.4,1 \mathrm{H}, \mathrm{H}_{5-\mathrm{py}}\right), 3.4-3.2(\mathrm{~m}, 6 \mathrm{H}$, $\mathrm{CHMe}_{\text {IPr }}$ and $\left.=\mathrm{CH}_{\text {coe }}\right), 2.0-1.2\left(\mathrm{~m}, 12 \mathrm{H}, \mathrm{CH}_{2-\text { coe }}\right), 1.64$ and 1.05 (both d, $J_{\mathrm{H}-\mathrm{H}}=6.8,24 \mathrm{H}, \mathrm{CHMe}{ }_{\mathrm{IPr}}$ ). ${ }^{13} \mathrm{C}\left\{{ }^{1} \mathrm{H}\right\}$-APT NMR $\left(100 \mathrm{MHz}, \mathrm{C}_{6} \mathrm{D}_{6}, 298 \mathrm{~K}\right): \delta 185.2\left(\mathrm{~d}, J_{\mathrm{C}-\mathrm{Rh}}=60.9, \mathrm{Rh}-\mathrm{C}_{\mathrm{IPr}}\right)$, $184.7\left(\mathrm{~d}, J_{\mathrm{C}-\mathrm{Rh}}=4.1, \mathrm{C}_{2-\mathrm{py}}\right), 146.8\left(\mathrm{~s}, \mathrm{C}_{\mathrm{q}-\mathrm{IPr}}\right), 146.5\left(\mathrm{~s}, \mathrm{C}_{6-\mathrm{py}}\right)$, $138.0\left(\mathrm{~s}, \mathrm{C}_{\mathrm{q}} \mathrm{N}\right), 135.1\left(\mathrm{~s}, \mathrm{C}_{4-\mathrm{py}}\right), 129.7$ and 124.1 (both $\mathrm{s}$, $\left.\mathrm{CH}_{\mathrm{Ph}-\mathrm{IPr}}\right), 126.7\left(\mathrm{~s}, \mathrm{C}_{3-\mathrm{py}}\right), 124.6\left(\mathrm{~d}, J_{\mathrm{C}-\mathrm{Rh}}=1.2,=\mathrm{CHN}_{\mathrm{IPr}}\right.$ ), $114.9\left(\mathrm{~s}, \mathrm{C}_{5-\mathrm{py}}\right), 64.1\left(\mathrm{~d}, J_{\mathrm{C}-\mathrm{Rh}}=14.1,=\mathrm{CH}_{\mathrm{coe}}\right), 30.5$ and 29.7 (both d, $\left.J_{\mathrm{C}-\mathrm{Rh}}=1.0, \mathrm{CH}_{2 \text {-coe }}\right), 29.3\left(\mathrm{~s}, \underline{\mathrm{CHMe}} \mathrm{HPr}_{\mathrm{IP}}\right), 27.0$ (s, $\mathrm{CH}_{\text {2-coe }}$ ), 26.5 and 23.5 (both s, $\mathrm{CHMe}$ IPr $) .{ }^{1} \mathrm{H}-{ }^{15} \mathrm{~N}$ HMQC $\operatorname{NMR}\left(40.5 \mathrm{MHz}, \mathrm{C}_{6} \mathrm{D}_{6}, 298 \mathrm{~K}\right): \delta 235.7\left(\mathrm{~N}_{\mathrm{py}}\right), 191.9\left(\mathrm{~N}_{\mathrm{IPr}}\right)$.

In Situ Formation of $\mathrm{Rh}\left\{\boldsymbol{\kappa}^{2}-\mathrm{S}, \boldsymbol{N}-(\mathrm{Spy})\right\}\left(\boldsymbol{\eta}^{2}-\mathrm{HC} \equiv \mathrm{CPh}\right)-$ (IPr) (6). A solution of $5(25 \mathrm{mg}, 0.035 \mathrm{mmol})$ in toluene- $d_{8}$ at $233 \mathrm{~K}(0.5 \mathrm{~mL}$, NMR tube) was treated with phenylacetylene $(6 \mu \mathrm{L}, 0.053 \mathrm{mmol})$. NMR spectra were recorded immediately at low temperature. ${ }^{1} \mathrm{H}$ NMR $\left(400.2 \mathrm{MHz}\right.$, toluene- $\left.d_{8}, 233 \mathrm{~K}\right)$ : $\delta 7.64\left(\mathrm{~d}, \mathrm{~J}_{\mathrm{H}-\mathrm{H}}=6.8,2 \mathrm{H}, \mathrm{H}_{\mathrm{o}-\mathrm{Ph}}\right), 7.3-6.9\left(9 \mathrm{H}, \mathrm{H}_{\mathrm{Ph}}\right), 6.73(\mathrm{dd}$, $\left.J_{\mathrm{H}-\mathrm{H}}=5.1,1.7,1 \mathrm{H}, \mathrm{H}_{6-\mathrm{py}}\right), 6.49\left(\mathrm{~s}, 2 \mathrm{H},=\mathrm{CHN}_{\mathrm{IPr}}\right), 6.33(\mathrm{dd}$, $\left.J_{\mathrm{H}-\mathrm{H}}=7.8,1.7,1 \mathrm{H}, \mathrm{H}_{3-\mathrm{py}}\right), 6.24\left(\mathrm{ddd}, J_{\mathrm{H}-\mathrm{H}}=7.8,7.1,1.7,1 \mathrm{H}\right.$, $\mathrm{H}_{4-p y}$ ), 5.55 (ddd, $\left.J_{\mathrm{H}-\mathrm{H}}=7.1,5.1,1.7,1 \mathrm{H}, \mathrm{H}_{5-\mathrm{py}}\right), 4.54$ (d, $J_{\mathrm{H}-\mathrm{Rh}}=2.3,1 \mathrm{H}, \eta^{2}-\underline{\mathrm{H}} \mathrm{C} \equiv \mathrm{CPh}$ ), 3.63 and 2.82 (both sept, $J_{\mathrm{H}-\mathrm{H}}$ $\left.=6.8,4 \mathrm{H}, \mathrm{CHMe}_{\mathrm{IPr}}\right), 1.75,1.48,1.08$, and $1.04\left(\right.$ all d, $J_{\mathrm{H}-\mathrm{H}}=$ 6.8, 24H, CHMe $\left.{ }_{\text {IPr }}\right) .{ }^{13} \mathrm{C}\left\{{ }^{1} \mathrm{H}\right\}-\mathrm{APT}$ NMR (100.4 MHz, toluene- $\left.d_{8}, 233 \mathrm{~K}\right): \delta 184.9\left(\mathrm{~d}, J_{\mathrm{C}-\mathrm{Rh}}=56.8, \mathrm{Rh}-\mathrm{C}_{\mathrm{IPr}}\right)$, $181.9\left(\mathrm{~d}, J_{\mathrm{C}-\mathrm{Rh}}=4.0, \mathrm{C}_{2-\mathrm{py}}\right.$ ), 145.8 and 145.3 (both s, $\mathrm{C}_{\mathrm{q}-\mathrm{IPr}}$ ), $142.3\left(\mathrm{~s}, \mathrm{C}_{6-\mathrm{py}}\right), 137.0\left(\mathrm{~s}, \mathrm{C}_{\mathrm{q}} \mathrm{N}\right), 135.8\left(\mathrm{~s}, \mathrm{C}_{4-\mathrm{py}}\right), 130.8,129.3$, 128.7, 128.6, 128.4, and 127.1 (all s, $\left.\mathrm{CH}_{\mathrm{Ph}}\right), 125.2$ (s, $\mathrm{C}_{3-\mathrm{py}}$ ), $123.9\left(\mathrm{~s},=\mathrm{CHN}_{\mathrm{IPr}}\right), 123.2\left(\mathrm{~s}, \mathrm{C}_{\mathrm{q}-\mathrm{Ph}}\right), 115.0\left(\mathrm{~s}, \mathrm{C}_{5-\mathrm{py}}\right), 89.2(\mathrm{~d}$, $\left.J_{\mathrm{C}-\mathrm{Rh}}=15.6, \mathrm{HC} \equiv \underline{\mathrm{CPh}}\right), 81.9\left(\mathrm{~d}, J_{\mathrm{C}-\mathrm{Rh}}=14.1, \mathrm{HC} \equiv \mathrm{CPh}\right)$, 29.1 and 28.9 (both s, $\underline{\mathrm{C}} \mathrm{HMe}_{\mathrm{IPr}}$ ), 26.5, 25.7, 23.3, and 22.8 (all s, $\left.\mathrm{CHMe} \mathrm{IPr}_{\mathrm{IP}}\right)$.

In Situ Formation of $\mathrm{Rh}\left\{\boldsymbol{\kappa}^{2}-\mathrm{O}, \mathrm{N}-(\mathrm{Oppy})\right\}\left\{\eta^{2}-\mathrm{H}_{2} \mathrm{C}=\mathrm{C}\right.$ (Mes) $\mathrm{C} \equiv \mathrm{C}($ Mes) $\}$ (IPr) (7). A solution of 2 (30 mg, 0.043 $\mathrm{mmol})$ in toluene- $d_{8}$ at $243 \mathrm{~K}(0.5 \mathrm{~mL}$, NMR tube $)$ was treated with 2-ethynyl-1,3,5-trimethylbenzene $(21 \mu \mathrm{L}, 0.129$ $\mathrm{mmol}$ ). NMR spectra were recorded immediately at low temperature. ${ }^{1} \mathrm{H}$ NMR $\left(300.1 \mathrm{MHz}\right.$, toluene- $\left.d_{8}, 298 \mathrm{~K}\right): \delta$ 7.5-6.5 (m, 10H, $\left.\mathrm{H}_{\mathrm{Ph}}\right), 6.80\left(\mathrm{~m}, 1 \mathrm{H}, \mathrm{H}_{5-\mathrm{py}}\right), 6.65$ and 6.62 (both br, $\left.2 \mathrm{H},=\mathrm{CHN}_{\mathrm{IPr}}\right), 5.76\left(\mathrm{dt}, J_{\mathrm{H}-\mathrm{H}}=8.5,1.1,1 \mathrm{H}, \mathrm{H}_{6-\mathrm{py}}\right.$ ), $5.54\left(\mathrm{ddd}, J_{\mathrm{H}-\mathrm{H}}=6.8,5.3,1.0,1 \mathrm{H}, \mathrm{H}_{4-\mathrm{py}}\right), 5.25\left(\mathrm{dt}, J_{\mathrm{H}-\mathrm{H}}=5.3\right.$, 
1.1, $1 \mathrm{H}, \mathrm{H}_{3-\mathrm{py}}$ ), 3.97, 3.95, 3.50, and 2.85 (all sept, $J_{\mathrm{H}-\mathrm{H}}=6.7$, $4 \mathrm{H}, \mathrm{CHMe}_{\mathrm{IPr}}$ ), 3.27 and 3.07 (both dd, $J_{\mathrm{H}-\mathrm{H}}=2.2, J_{\mathrm{H}-\mathrm{Rh}}=1.0$, $\left.2 \mathrm{H}, \mathrm{CH}_{2-\pi \text {-enyne }}\right), 2.3-2.0\left(18 \mathrm{H}, \mathrm{Me}_{\pi \text {-enyne }}\right), 1.80,1.57,1.55$, $1.30,1.14,1.11,1.08$, and $1.02\left(\right.$ all $\mathrm{d}, J_{\mathrm{H}-\mathrm{H}}=6.7,24 \mathrm{H}$, $\left.\mathrm{CHMe}_{\mathrm{IPr}}\right) .{ }^{13} \mathrm{C}\left\{{ }^{1} \mathrm{H}\right\}$-APT NMR $\left(75.5 \mathrm{MHz}\right.$, toluene- $d_{8}, 243$ $\mathrm{K}): \delta 185.0\left(\mathrm{~d}, J_{\mathrm{C}-\mathrm{Rh}}=60.1, \mathrm{Rh}-\mathrm{C}_{\mathrm{IPr}}\right), 181.4\left(\mathrm{~d}, J_{\mathrm{C}-\mathrm{Rh}}=2.7\right.$, $\mathrm{C}_{2-\mathrm{py}}$ ), 150.0, 148.2, 146.6, and 145.3 (all s, $\mathrm{C}_{\mathrm{q}-\mathrm{IPr}}$ ), 142.4 (s, $\mathrm{C}_{3-\mathrm{py}}$ ), 142-134 (all s, $\left.\mathrm{C}_{\mathrm{q}-\mathrm{Ph}-\pi \text {-enyne }}\right), 139.0\left(\mathrm{~s}, \mathrm{C}_{5 \text {-py }}\right), 138.9$ and 137.1 (both s, $\left.\mathrm{C}_{\mathrm{q}} \mathrm{N}\right), 131-123\left(\right.$ all s, $\left.\mathrm{CH}_{\mathrm{Ph}}\right), 128.4(\mathrm{~s},=$ $\left.\mathrm{CHN}_{\mathrm{IPr}}\right), 110.1\left(\mathrm{~s}, \mathrm{PhC} \equiv \mathrm{CC}(\mathrm{Ph})=\mathrm{CH}_{2}\right), 109.8\left(\mathrm{~s}, \mathrm{C}_{6-\mathrm{py}}\right)$, $109.0\left(\mathrm{~s}, \mathrm{C}_{4-\mathrm{py}}\right), 83.2\left(\mathrm{~s}, \mathrm{Ph} \underline{\mathrm{C}} \equiv \mathrm{CC}(\mathrm{Ph})=\mathrm{CH}_{2}\right), 50.3\left(\mathrm{~d}, J_{\mathrm{C}-\mathrm{Rh}}\right.$ $\left.=17.9,=\mathrm{CH}_{2}\right), 41.0\left(\mathrm{~d}, J_{\mathrm{C}-\mathrm{Rh}}=17.8, \underline{\mathrm{C}}=\mathrm{CH}_{2}\right), 30.3,29.4$, 28.8, and 28.7 (all s, $\underline{\mathrm{C} H M \mathrm{IPr}_{\mathrm{Ir}}}$ ), 29-20 (all s, $\mathrm{Me}_{\pi \text {-enyne }}$ ), 28.4, 28.3, 26.8, 26.6, 24.0, 23.5, 23.4, and 21.6 (all s, $\mathrm{CHMe} \mathrm{IPr}_{\mathrm{Ir}}$ ).

In Situ Formation of $\mathrm{Rh}\left[\kappa^{1}-\mathrm{O}-\{\mathrm{O}=\mathrm{C}(-\mathrm{CH}=\mathrm{CH}-\mathrm{CH}=\right.$ $\mathrm{CH}-) \mathrm{NH}\}]\left\{\kappa^{1}-\mathrm{O}-\left(\mathrm{CF}_{3} \mathrm{O}_{3} \mathrm{~S}\right)\right\}\left(\eta^{2}-\mathrm{coe}\right)(\mathrm{IPr})(8 \mathrm{a}, \mathrm{b})$. A solution of $2(23 \mathrm{mg}, 0.033 \mathrm{mmol})$ in $\mathrm{CD}_{2} \mathrm{Cl}_{2}$ at $223 \mathrm{~K}(0.5 \mathrm{~mL}, \mathrm{NMR}$ tube) was treated with trifluoromethanesulfonic acid $(3 \mu \mathrm{L}$, $0.033 \mathrm{mmol}$ ). NMR spectra were recorded immediately at low temperature. NMR data evidenced the presence of an equilibrium mixture of two isomers, $\mathbf{8 a}$ and $\mathbf{8 b}$ (50:50). Data for complex 8a: ${ }^{1} \mathrm{H}$ NMR (400.1 MHz, $\left.\mathrm{CD}_{2} \mathrm{Cl}_{2}, 223 \mathrm{~K}\right): \delta$ $11.73(\mathrm{~s}, 1 \mathrm{H}, \mathrm{NH}), 7.8-7.1\left(\mathrm{~m}, 6 \mathrm{H}, \mathrm{H}_{\mathrm{Ph}, \mathrm{IPr}}\right), 7.67(\mathrm{~m}, 1 \mathrm{H}$, $\left.\mathrm{H}_{6-\mathrm{py}}\right), 7.52\left(\mathrm{~m}, 1 \mathrm{H}, \mathrm{H}_{4-\mathrm{py}}\right), 7.06\left(\mathrm{~s}, 2 \mathrm{H},=\mathrm{CHN}_{\mathrm{IPr}}\right), 6.85(\mathrm{~d}$, $\left.J_{\mathrm{H}-\mathrm{H}}=9.0,1 \mathrm{H}, \mathrm{H}_{3-\mathrm{py}}\right), 6.43\left(\mathrm{~m}, 1 \mathrm{H}, \mathrm{H}_{5-\mathrm{py}}\right), 3.55$ and 2.75 (both sept, $\left.J_{\mathrm{H}-\mathrm{H}}=6.8,4 \mathrm{H}, \mathrm{CHMe}_{\mathrm{IPr}}\right), 2.9-2.7(\mathrm{~m}, 2 \mathrm{H},=$ $\left.\mathrm{CH}_{\text {coe }}\right), 1.6-1.0\left(\mathrm{~m}, 36 \mathrm{H}, \mathrm{CH}_{2 \text {-coe }}\right.$ and $\left.\mathrm{CHMe}{ }_{\mathrm{IPr}}\right) .{ }^{13} \mathrm{C}\left\{{ }^{1} \mathrm{H}\right\}-$ APT NMR $\left(100.6 \mathrm{MHz}, \mathrm{CD}_{2} \mathrm{Cl}_{2}, 223 \mathrm{~K}\right): \delta 177.0$ (d, $J_{\mathrm{C}-\mathrm{Rh}}=$ 62.1, $\mathrm{Rh}-\mathrm{C}_{\mathrm{IPr}}$ ), $165.2\left(\mathrm{~s}, \mathrm{C}_{2-\mathrm{py}}\right.$ ), 147.0 and 146.9 (both $\mathrm{s}$, $\left.\mathrm{C}_{\mathrm{q}-\mathrm{IPr}}\right), 142.7\left(\mathrm{~s}, \mathrm{C}_{4-\mathrm{py}}\right), 136.1\left(\mathrm{~s}, \mathrm{C}_{\mathrm{q}} \mathrm{N}\right), 135.9\left(\mathrm{~s}, \mathrm{C}_{6-\mathrm{py}}\right), 130-$ 123 (all s, $\mathrm{CH}_{\mathrm{Ph}-\mathrm{IPr}}$ ), 120.0 (s, $\mathrm{C}_{3-\mathrm{py}}$ ), 109.7 (s, $\mathrm{C}_{5-\mathrm{py}}$ ), 66.9 (d, $J_{\mathrm{C}-\mathrm{Rh}}=14.0,=\mathrm{CH}_{\text {coe }}$ ), 33-25 (all s, $\mathrm{CH}_{2-\mathrm{coe}}$ ), 29.0 and 28.4 (both s, $\underline{\mathrm{C} H M e_{\mathrm{IPr}}}$ ), 26.2, 22.5, 22.2, and 22.0 (all s, $\mathrm{CHMe} \underline{\mathrm{IPr}}_{\mathrm{Ir}}$ ). ${ }^{1} \mathrm{H}-{ }^{15} \mathrm{~N}$ HMQC NMR (40.5 MHz, $\left.\mathrm{C}_{6} \mathrm{D}_{6}, 233 \mathrm{~K}\right): \delta 174.0$ $\left(\mathrm{NH}_{\mathrm{py}}\right) .{ }^{19} \mathrm{~F}$ NMR $\left(282.3 \mathrm{MHz}, \mathrm{CD}_{2} \mathrm{Cl}_{2}, 223 \mathrm{~K}\right): \delta-77.9$ and -79.2 (both br, $\mathrm{CF}_{3}$ ). Data for complex 8b: ${ }^{1} \mathrm{H}$ NMR (400.1 $\left.\mathrm{MHz}, \mathrm{CD}_{2} \mathrm{Cl}_{2}, 223 \mathrm{~K}\right): \delta 10.97(\mathrm{~s}, 1 \mathrm{H}, \mathrm{NH}), 7.8-7.1(\mathrm{~m}, 6 \mathrm{H}$, $\left.\mathrm{H}_{\mathrm{Ph}, \mathrm{IPr}}\right), 7.37\left(\mathrm{~m}, 1 \mathrm{H}, \mathrm{H}_{6-\mathrm{py}}\right), 7.30\left(\mathrm{~m}, 1 \mathrm{H}, \mathrm{H}_{4-\mathrm{py}}\right), 7.06(\mathrm{~s}, 2 \mathrm{H}$, $\left.=\mathrm{CHN}_{\mathrm{IPr}}\right), 6.45\left(\mathrm{~m}, 1 \mathrm{H}, \mathrm{H}_{3-\mathrm{py}}\right), 6.43\left(\mathrm{~m}, 1 \mathrm{H}, \mathrm{H}_{5-\mathrm{py}}\right), 2.66$ and 2.27 (both br, 4H, $\left.\underline{\mathrm{HMe}}_{\mathrm{IPr}}\right), 2.9-2.7\left(\mathrm{~m}, 2 \mathrm{H},=\mathrm{CH}_{\text {coe }}\right), 1.6-$ $1.0\left(\mathrm{~m}, 36 \mathrm{H}, \mathrm{CH}_{2 \text {-coe }}\right.$ and $\mathrm{CHMe}$ IPr $) .{ }^{13} \mathrm{C}\left\{{ }^{1} \mathrm{H}\right\}-\mathrm{APT}$ NMR $\left(100.6 \mathrm{MHz}, \mathrm{CD}_{2} \mathrm{Cl}_{2}, 223 \mathrm{~K}\right): \delta 177.0\left(\mathrm{~d}, J_{\mathrm{C}-\mathrm{Rh}}=62.1, \mathrm{Rh}-\right.$ $\mathrm{C}_{\text {IPr }}$ ), $164.6\left(\mathrm{~s}, \mathrm{C}_{2-\mathrm{py}}\right), 146.0\left(\mathrm{~s}, \mathrm{C}_{\mathrm{q}-\mathrm{IPr}}\right), 142.5$ ( $\left.\mathrm{s}, \mathrm{C}_{4-\mathrm{py}}\right), 135.5$ $\left(\mathrm{s}, \mathrm{C}_{\mathrm{q}} \mathrm{N}\right), 135.1\left(\mathrm{~s}, \mathrm{C}_{6-\mathrm{py}}\right), 130-123\left(\right.$ all s, $\left.\mathrm{CH}_{\mathrm{Ph}-\mathrm{IPr}}\right), 119.9$ (s, $\left.\mathrm{C}_{3-\mathrm{py}}\right), 108.6\left(\mathrm{~s}, \mathrm{C}_{5-\mathrm{py}}\right), 66.9\left(\mathrm{~d}, \mathrm{~J}_{\mathrm{C}-\mathrm{Rh}}=14.0,=\mathrm{CH}_{\text {coe }}\right), 33-25$ (all s, $\mathrm{CH}_{2-\text { coe }}$ ), 29.0 and 28.4 (both s, $\underline{\mathrm{C}} \mathrm{HMe}_{\mathrm{IPr}}$ ), 26.2, 22.5, 22.2, and 22.0 (all s, $\mathrm{CHMe}_{\mathrm{IPr}}$ ). ${ }^{1} \mathrm{H}-{ }^{15} \mathrm{~N} \mathrm{HMQC}$ NMR (40.5 $\left.\mathrm{MHz}, \mathrm{CD}_{2} \mathrm{Cl}_{2}, 223 \mathrm{~K}\right): \delta 170.3\left(\mathrm{NH}_{\mathrm{py}}\right) .{ }^{19} \mathrm{~F} \mathrm{NMR}(282.3$ $\mathrm{MHz}, \mathrm{CD}_{2} \mathrm{Cl}_{2}, 223 \mathrm{~K}$ ): $\delta-77.9$ and -79.2 (both br, $\mathrm{CF}_{3}$ ).

Standard Conditions for the Catalytic Alkyne Dimerization. To a $\mathrm{C}_{6} \mathrm{D}_{6}$ solution $(0.5 \mathrm{~mL})$ in a NMR tube under argon atmosphere, $0.01 \mathrm{mmol}$ of catalyst and $0.17 \mathrm{mmol}$ of toluene as internal standard were added. The solution was frozen by means of a dewar flask containing isopropanol at 195 $\mathrm{K}$. Then, $0.50 \mathrm{mmol}$ of alkyne were added and the NMR tube was sealed under argon. The solution was allowed to warm up to room temperature just before the first NMR spectrum was recorded. The reaction course was monitored by ${ }^{1} \mathrm{H}$ NMR spectroscopy, and the conversion was determined by integration of the corresponding resonances of the internal standard and the products. In case of $0.5,0.1$, or $0.05 \mathrm{~mol} \%$ of catalyst loading, a $20 \mathrm{mM}$ solution of catalyst in $\mathrm{C}_{6} \mathrm{D}_{6}$ was prepared, and then, the corresponding amount of solution was added to the reaction mixture and it was proceeded as described above.

Crystal Structure Determination. Single crystals of $\mathbf{2}$ suitable for the X-ray diffraction studies were grown by slow diffusion of hexane into a toluene solution of the compound. X-ray diffraction data were collected at $100(2) \mathrm{K}$ on a Bruker APEX SMART CCD diffractometer with graphite-monochromated Mo-K $\alpha$ radiation $(\lambda=0.71073 \AA)$ using $0.6^{\circ} \omega$ rotations. Intensities were integrated and corrected for absorption effects with SAINT-PLUS ${ }^{35}$ and SADABS $^{36}$ programs, both included in the APEX2 package. The structures were solved by the Patterson method with SHELXS- $97^{37}$ and refined by full matrix least-squares on $F^{2}$ with SHELXL-2014, ${ }^{38}$ under WinGX. ${ }^{39}$

Crystal Data and Structure Refinement for 2. $\mathrm{C}_{40} \mathrm{H}_{54} \mathrm{~N}_{3} \mathrm{ORh}, 695.77 \mathrm{~g} \mathrm{~mol}^{-1}$, Monoclinic, $P 2_{1} / c, a=$ 11.2672(10) $\AA, b=10.7013(10) \AA, c=29.775(3) \AA, b=$ 90.3070(10) $)^{\circ}, V=3590.0(6) \AA^{3}, Z=4, D_{\text {calc }}=1.287 \mathrm{~g} \mathrm{~cm}^{-3}, \mu$ $=0.510 \mathrm{~mm}^{-1}, F(000)=1472, \theta_{\min } / \theta_{\max }=1.807 / 25.680^{\circ}$, index ranges $-13 \leq h \leq 13,-13 \leq k \leq 13,-36 \leq l \leq 36$, reflections collected/independent 36521/6806 $[R($ int $)=$ $0.0410]$, data/restraints/parameters $6806 / 13 / 452, \operatorname{GooF}\left(F^{2}\right)$ $1.041, R_{1}=0.0282[I>2 \sigma(I)], w R_{2}=0.0635$ (all data), largest diff. peak/hole $0.350 /-0.422 \mathrm{e} \cdot \AA^{-3}$. CCDC deposition number 2015873.

Computational Details. All DFT theoretical calculations were carried out using the Gaussian program package. ${ }^{40}$ The B97D3 exchange correlation functional ${ }^{41}$ has been employed for the calculation of energies, gradients, and frequencies in combination to the def2-SVP basis set ${ }^{42}$ which considers effective core potentials for $\mathrm{Rh}$. Single point calculations at the M06L/def-TZVP level of theory, ${ }^{43}$ including also the SMD approach $^{44}$ for benzene to simulate solvation effects were performed to refine the energetic values. All calculations were done using the "ultrafine" grid. Relative energies are Gibbs free energies referred to a $1 \mathrm{M}$ standard state using the approximation of Goddard et al. ${ }^{45}$ at $25{ }^{\circ} \mathrm{C}$. Analytical frequency analyses were employed to confirm the nature of the stationary points. An intrinsic reaction path or coordinate scan calculations connecting both minima were performed for flat or unclear transition states.

\section{ASSOCIATED CONTENT}

\section{Supporting Information}

The Supporting Information is available free of charge at https://pubs.acs.org/doi/10.1021/acscatal.1c00602.

Miscellaneous information including NMR data of complexes and organic products, deuterium labeling experiments, and DFT calculation data (PDF)

Crystallographic information file for CCDC 2015873 (CIF)

Optimized coordinates for the computed compounds (XYZ)

\section{AUTHOR INFORMATION}

\section{Corresponding Authors}

Ricardo Castarlenas - Departamento de Química Inorgánica-Instituto de Síntesis Química y Catálisis Homogénea (ISQCH), Universidad de Zaragoza-CSIC, 50009 Zaragoza, Spain; 이이.org/0000-0003-44608678; Email: rcastar@unizar.es 
Víctor Polo - Departamento de Química Física, Universidad de Zaragoza, 50009 Zaragoza, Spain; (1) orcid.org/00000001-5823-7965; Email: vipolo@unizar.es

\section{Authors}

María Galiana-Cameo - Departamento de Química Inorgánica-Instituto de Síntesis Química y Catálisis Homogénea (ISQCH), Universidad de Zaragoza-CSIC, 50009 Zaragoza, Spain; @ orcid.org/0000-0002-20434864

Asier Urriolabeitia - Departamento de Química Física, Universidad de Zaragoza, 50009 Zaragoza, Spain

Eduardo Barrenas - Departamento de Química Inorgánica-Instituto de Sintesis Química y Catálisis Homogénea (ISQCH), Universidad de Zaragoza-CSIC, 50009 Zaragoza, Spain

Vincenzo Passarelli - Centro Universitario de la Defensa, 50090 Zaragoza, Spain; Departamento de Química Inorgánica-Instituto de Síntesis Química y Catálisis Homogénea (ISQCH), Universidad de Zaragoza-CSIC, 50009 Zaragoza, Spain; orcid.org/0000-0002-17356439

Jesús J. Pérez-Torrente - Departamento de Química Inorgánica-Instituto de Síntesis Química y Catálisis Homogénea (ISQCH), Universidad de Zaragoza-CSIC, 50009 Zaragoza, Spain; 10 orcid.org/0000-0002-33270918

Andrea Di Giuseppe - Departamento de Química Inorgánica-Instituto de Síntesis Química y Catálisis Homogénea (ISQCH), Universidad de Zaragoza-CSIC, 50009 Zaragoza, Spain; Dipartimento di Scienze Fisiche e Chimiche, Università dell'Aquila, I-67100 Coppito, AQ Italy; ○ orcid.org/0000-0002-3666-5800

Complete contact information is available at: https://pubs.acs.org/10.1021/acscatal.1c00602

\section{Notes}

The authors declare no competing financial interest.

\section{ACKNOWLEDGMENTS}

Financial support from the Spanish Ministerio de Ciencia e Innovación (MICINN/FEDER) under the Projects PID2019103965GB-I00 and PGC2018-099383-B-I00, and the Diputación General de Aragón (FEDER 2014-2020 "Building Europe from Aragón”, group E42_20R) are gratefully acknowledged. A.D.G. thanks the Spanish Ministerio de Economía y Competitividad (MINECO) for the postdoctoral grant Juan de la Cierva - Incorporación 2015 (IJCI-2015-27029). A.U. thankfully acknowledges the Spanish MECD for a FPU fellowship (FPU 2017/05417). The authors would like to acknowledge the use of Servicio General de Apoyo a la Investigación-SAI, Universidad de Zaragoza and the computational resources provided by the Institute for Biocomputation and the Physics of Complex Systems (BIFI)-Universidad de Zaragoza.

\section{DEDICATION}

Dedicated to Prof. Pierre H. Dixneuf, a very active species who initiated the catalytic cycles of many researchers.

\section{REFERENCES}

(1) Hayler, J. D.; Leahy, D. K.; Simmons, E. M. A. Pharmaceutical Industry Perspective on Sustainable Metal Catalysis. Organometallics 2019, 38, 36-46.

(2) (a) Ikariya, T.; Murata, K.; Noyori, R. Bifunctional Transition Metal-Based Molecular Catalysts for Asymmetric Syntheses. Org. Biomol. Chem. 2006, 4, 393-406. (b) Grotjahn, D. B. Bifunctional Catalysts and Related Complexes: Structures and Properties. Dalton Trans. 2008, 6497-6508. (c) Khusnutdinova, J. R.; Milstein, D. Metal-Ligand Cooperation. Angew. Chem., Int. Ed. 2015, 54, 1223612273. (d) Kim, D.-S.; Park, W.-J.; Jun, C.-H. Metal-Organic Cooperative Catalysis in C-H and C-C Bond Activation. Chem. Rev. 2017, 117, 8977-9015. (e) Higashi, T.; Kusumoto, S.; Nozaki, K. Cleavage of $\mathrm{Si}-\mathrm{H}, \mathrm{B}-\mathrm{H}$, and C-H bonds by Metal-Ligand cooperation. Chem. Rev. 2019, 119, 10393-10402.

(3) Johnson, D. G.; Lynam, J. M.; Slattery, J. M.; Welby, C. E. Insights into the Intramolecular Acetate-Mediated Formation of Ruthenium Vinylidene Complexes: a Ligand-Assisted Proton Shuttle (LAPS) Mechanism. Dalton Trans. 2010, 39, 10432-10441.

(4) (a) Breit, B.; Gellrich, U.; Li, T.; Lynam, J. M.; Milner, L. M.; Pridmore, N. E.; Slattery, J. M.; Whitwood, A. C. Mechanistic Insight into the Ruthenium-Catalysed anti-Markovnikov Hydration of Alkynes Using a Self-Assembled Complex: a Crucial Role for Ligand-Assisted Proton Shuttle Processes. Dalton Trans. 2014, 43, 11277-11285. (b) Leeb, N. M.; Drover, M. W.; Love, J. A.; Schafer, L. L.; Slattery, J. M. Phosphoramidate-Assisted Alkyne Activation: Probing the Mechanism of Proton Shuttling in a N,O-Chelated Cp*Ir(III) Complex. Organometallics 2018, 37, 4630-4638. (c) Zafar, M.; Ramalakshmi, R.; Pathak, K.; Ahmad, A.; Roisnel, T.; Ghosh, S. Five-Membered Ruthenacycles: Ligand-Assisted Alkyne Insertion into 1,3-N,S-Chelated Ruthenium Borate Species. Chem. Eur. J. 2019, 25, 13537-13546.

(5) (a) Monot, J.; Brunel, P.; Kefalidis, C. E.; Espinosa-Jalapa, N. A.; Maron, L.; Martin-Vaca, B.; Bourissou, D. A Case Study of Proton Shuttling in Palladium Catalysis. Chem. Sci. 2016, 7, 2179-2187. (b) El-Sepelgy, O.; Brzozowska, A.; Azofra, L. M.; Jang, Y. K.; Cavallo, L.; Rueping, M. Experimental and Computational Study of an Unexpected Iron-Catalyzed Carboetherification by Cooperative Metal and Ligand Substrate Interaction and Proton Shuttling. Angew. Chem., Int. Ed. 2017, 56, 14863-14867.

(6) de Aguirre, A.; Díez-González, S.; Maseras, F.; Martín, M.; Sola, E. The Acetate Proton Shuttle between Mutually Trans Ligands. Organometallics 2018, 37, 2645-2651.

(7) (a) Crawford, L.; Cole-Hamilton, D. J.; Drent, E.; Bühl, M. Mechanism of Alkyne Alkoxycarbonylation at a Pd Catalyst with P,N Hemilabile Ligands: A Density Functional Study. Chem. - Eur. J. 2014, 20, 13923-13926. (b) Virant, M.; Mihelač, M.; Gazvoda, M.; Cotman, A. E.; Frantar, A.; Pinter, B.; Košmrlj. Pyridine Wingtip in $\left[\mathrm{Pd}(\text { Py-tzNHC })_{2}\right]_{2}{ }^{+}$Complex Is a Proton Shuttle in the Catalytic Hydroamination of Alkynes. Org. Lett. 2020, 22, 2157-2161. (c) Zhu, L.; Liu, L.-J.; Jiang, Y.-Y.; Liu, P.; Fan, X.; Zhang, Q.; Zhao, Y.; Bi, S. Mechanism and Origin of Ligand-Controlled Chemo- and Regioselectivities in Palladium-Catalyzed Methoxycarbonylation of Alkynes. J. Org. Chem. 2020, 85, 7136-7151.

(8) (a) García-Garrido, S. E. Modern Alkyne Chemistry: Catalytic and Atom-Economic Transformations; Trost, B. M., Li, C.-J., Eds.; WileyVCH: Weinheim, Germany, 2015; pp 301-334. (b) Trost, B. M.; Masters, J. T. Transition Metal-Catalyzed Couplings of Alkynes to 1,3-Enynes: Modern Methods and Synthetic Applications. Chem. Soc. Rev. 2016, 45, 2212-2238. (c) Temkin, O. N. Golden Age" of Homogeneous Catalysis Chemistry of Alkynes: Dimerization and Oligomerization of Alkynes. Kinet. Catal. 2019, 60, 689-732. (d) Liang, Q.; Hayashi, K.; Song, D. Catalytic Alkyne Dimerization without Noble Metals. ACS Catal. 2020, 10, 4895-4905.

(9) (a) Duchateau, R.; van Wee, C. T.; Teuben, J. H. Insertion and $\mathrm{C}-\mathrm{H}$ Bond Activation of Unsaturated Substrates by Bis(benzamidinato)yttrium Alkyl, $\left[\mathrm{PhC}\left(\mathrm{NSiMe}_{3}\right)_{2}\right]_{2} \mathrm{YR}(\mathrm{R}=$ $\mathrm{CH}_{2} \mathrm{Ph}$.THF, $\left.\mathrm{CH}\left(\mathrm{SiMe}_{3}\right)_{2}\right)$, and Hydrido, $\left\{\left[\mathrm{PhC}\left(\mathrm{NSiMe}_{3}\right)_{2}\right]_{2} \mathrm{Y}(\mu\right.$ $\mathrm{H})\}_{2}$, Compounds. Organometallics 1996, 15, 2291-2302. (b) Haskel, 
A.; Straub, T.; Dash, A. K.; Eisen, M. S. Oligomerization and CrossOligomerization of Terminal Alkynes Catalyzed by Organoactinide Complexes. J. Am. Chem. Soc. 1999, 121, 3014-3024. (c) Nishiura, M.; Hou, Z.; Wakatsuki, Y.; Yamaki, T.; Miyamoto, T. Novel ZSelective Head-to-Head Dimerization of Terminal Alkynes Catalyzed by Lanthanide Half-Metallocene Complexes. J. Am. Chem. Soc. 2003, 125, 1184-1185. (d) Batrice, R. J.; McKinven, J.; Arnold, P. L.; Eisen, M. S. Selective Oligomerization and $[2+2+2]$ Cycloaddition of Terminal Alkynes from Simple Actinide Precatalysts. Organometallics 2015, 34, 4039-4050.

(10) (a) Oshovsky, G. V.; Hessen, B.; Reek, J. N. H.; De Bruin, B. Electronic Selectivity Tuning in Titanium(III)-Catalyzed Acetylene Cross-Dimerization Reactions. Organometallics 2011, 30, 6067-6070. (b) Platel, R. H.; Schafer, L. L. Zirconium Catalyzed Alkyne Dimerization for Selective Z-Enyne Synthesis. Chem. Commun. 2012, 48, 10609-10611.

(11) (a) Trost, B. M.; Sorum, M. T.; Chan, C.; Ruhter, G. Palladium-Catalyzed Additions of Terminal Alkynes to Acceptor Alkynes. J. Am. Chem. Soc. 1997, 119, 698-708. (b) Rubina, M.; Gevorgyan, V. Can Agostic Interaction Affect Regiochemistry of Carbopalladation? Reverse Regioselectivity in the Palladium-Catalyzed Dimerization of Aryl Acetylenes. J. Am. Chem. Soc. 2001, 123, 11107-11108. (c) Katagiri, T.; Tsurugi, H.; Satoh, T.; Miura, M. Rhodium-Catalyzed (E)-Selective Cross-Dimerization of Terminal Alkynes. Chem. Commun. 2008, 3405-3407. (d) Chen, T.; Guo, C.; Goto, M.; Han, L.-B. A Brønsted Acid-Catalyzed Generation of Palladium Complexes: Efficient Head-to-Tail Dimerization of Alkynes. Chem. Commun. 2013, 49, 7498-7500. (e) Zatolochnaya, O. V.; Gordeev, E. G.; Jahier, C.; Ananikov, V. P.; Gevorgyan, V. Carboxylate Switch between Hydro- and Carbopalladation Pathways in Regiodivergent Dimerization of Alkynes. Chem. - Eur. J. 2014, 20, 9578-9588. (f) Salvio, R.; Juliá-Hernández, F.; Pisciottani, L.; Mendoza-Meroño, R.; García-Granda, S.; Bassetti, M. Kinetics and Mechanistic Insights into the Acetate-Assisted Dimerization of Terminal Alkynes under Ruthenium- and Acid-Promoted (RAP) Catalysis. Organometallics 2017, 36, 3830-3840. (g) Żak, P.; Bołt, M.; Lorkowski, J.; Kubicki, M.; Pietraszuk, C. Platinum Complexes Bearing Bulky N-Heterocyclic Carbene Ligands as Efficient Catalysts for the Fully Selective Dimerization of Terminal Alkynes. ChemCatChem 2017, 9, 3627-3631. (h) Storey, C. M.; Gyton, M. R.; Andrew, R. E.; Chaplin, A. B. Terminal Alkyne Coupling Reactions through a Ring: Mechanistic Insights and Regiochemical Switching. Angew. Chem., Int. Ed. 2018, 57, 12003-12006. (i) Galiana-Cameo, M.; Borraz, M.; Zelenkova, Y.; Passarelli, V.; Lahoz, F. J.; Pérez-Torrente, J. J.; Oro, L. A.; Di Giuseppe, A.; Castarlenas, R. Rhodium(I)-NHC Complexes Bearing Bidentate BisHeteroatomic Acidato Ligands as gem-Selective Catalysts for Alkyne Dimerization. Chem. - Eur. J. 2020, 26, 9598-9608. (j) Storey, C. M.; Gyton, M. R.; Andrew, R. E.; Chaplin, A. B. Terminal Alkyne Coupling Reactions Through a Ring: Effect of Ring Size on Rate and Regioselectivity. Chem. - Eur. J. 2020, 26, 14715-14723.

(12) (a) Dash, A. K.; Eisen, M. S. Chemo- and Regioselective Dimerization of Terminal Alkynes Promoted by Methylaluminoxane. Org. Lett. 2000, 2, 737-740. (b) Brar, A.; Mummadi, S.; Unruh, D. K.; Krempner, C. Verkade Base in FLP Chemistry-From Stoichiometric C-H Bond Cleavage to the Catalytic Dimerization of Alkynes. Organometallics 2020, 39, 4307-4311.

(13) (a) Midya, G. C.; Paladhi, S.; Dhara, K.; Dash, J. Iron Catalyzed Highly Regioselective Dimerization of Terminal Aryl Alkynes. Chem. Commun. 2011, 47, 6698-6700. (b) Ventre, S.; Derat, E.; Amatore, M.; Aubert, C.; Petit, M. Hydrido-Cobalt Catalyst as a Selective Tool for the Dimerisation of Arylacetylenes: Scope and Theoretical Studies. Adv. Synth. Catal. 2013, 355, 2584-2590. (c) Rivada-Wheelaghan, O.; Chakraborty, S.; Shimon, L. J. W. Y.; Ben-David, Y.; Milstein, D. Z-Selective (Cross-)Dimerization of Terminal Alkynes Catalyzed by an Iron Complex. Angew. Chem., Int. Ed. 2016, 55, 6942-6945. (d) Liang, Q.; Osten, K. M.; Song, D. Iron-Catalyzed gem-Specific Dimerization of Terminal Alkynes. Angew. Chem., Int. Ed. 2017, 56, 6317-632. (e) Gorgas, N.; Stöger, B.; Veiros, L. F.; Kirchner, K.
Iron(II) Bis(acetylide) Complexes as Key Intermediates in the Catalytic Hydrofunctionalization of Terminal Alkynes. ACS Catal. 2018, 8, 7973-7982. (f) Liang, Q.; Sheng, K.; Salmon, A.; Zhou, V. Y.; Song, D. Active Iron(II) Catalysts toward gem-Specific Dimerization of Terminal Alkynes. ACS Catal. 2019, 9, 810-818. (g) Zhuang, X.; Chen, J.-Y.; Yang, Z.; Jia, M.; Wu, C.; Liao, R.-Z.; Tung, C.-H.; Wang, W. Sequential Transformation of Terminal Alkynes to 1,3-Dienes by a Cooperative Cobalt Pyridonate Catalyst. Organometallics 2019, 38, 3752-3759. (h) Ueda, Y.; Tsurugi, H.; Mashima, K. Cobalt-Catalyzed E-Selective Cross-Dimerization of Terminal Alkynes: A Mechanism Involving Cobalt(0/II) Redox Cycles. Angew. Chem., Int. Ed. 2020, 59, 1552-1556. (i) Chen, J.-F.; $\mathrm{Li}$, C. Cobalt-Catalyzed gem-Cross-Dimerization of Terminal Alkynes. ACS Catal. 2020, 10, 3881-3889.

(14) (a) Hasenbeck, M.; Müller, T.; Gellrich, U. Metal-free gem Selective Dimerization of Terminal Alkynes Catalyzed by a Pyridonate Borane Complex. Catal. Sci. Technol. 2019, 9, 24382444. (b) Ahmed, J.; Swain, A. K.; Das, A.; Govindarajan, R.; Bhunia, M.; Mandal, S. K. A K-Arylacetylide Complex for Catalytic Terminal Alkyne Functionalization Using $\mathrm{KOtBu}$ as a Precatalyst. Chem. Commun. 2019, 55, 13860-13863.

(15) (a) Rubio-Pérez, L.; Azpíroz, R.; Di Giuseppe, A.; Polo, V.; Castarlenas, R.; Pérez-Torrente, J. J.; Oro, L. A. Pyridine-Enhanced Head-to-Tail Dimerization of Terminal Alkynes by a Rhodium-NHeterocyclic-Carbene Catalyst. Chem. - Eur. J. 2013, 19, 1530415314. (b) Azpíroz, R.; Rubio-Pérez, L.; Castarlenas, R.; PérezTorrente, J. J.; Oro, L. A. gem-Selective Cross-Dimerization and Cross-Trimerization of Alkynes with Silylacetylenes Promoted by a Rhodium-Pyridine-N-Heterocyclic Carbene Catalyst. ChemCatChem 2014, 6, 2587-2592.

(16) (a) Di Giuseppe, A.; Castarlenas, R.; Pérez-Torrente, J. J.; Lahoz, F. J.; Polo, V.; Oro, L. A. Mild and Selective H/D Exchange at the $\beta$ Position of Aromatic $\alpha$-Olefins by N-Heterocyclic CarbeneHydride-Rhodium Catalysts. Angew. Chem., Int. Ed. 2011, 50, 39383942. (b) Kwak, J.; Ohk, Y.; Jung, Y.; Chang, S. Rollover Cyclometalation Pathway in Rhodium Catalysis: Dramatic NHC Effects in the C-H Bond Functionalization. J. Am. Chem. Soc. 2012, 134, 17778-17788. (c) Keske, E. C.; Moore, B. D.; Zenkina, O. V.; Wang, R.; Schatte, G.; Crudden, C. M. Highly Selective Directed Arylation Reactions via Back-to-Back Dehydrogenative C-H Borylation/Arylation Reactions. Chem. Commun. 2014, 50, 9883-9886. (d) Palacios, L.; Meheut, Y.; Galiana-Cameo, M.; Artigas, M. J.; Di Giuseppe, A.; Lahoz, F. J.; Polo, V.; Castarlenas, R.; Pérez-Torrente, J. J.; Oro, L. A. Design of Highly Selective Alkyne Hydrothiolation $\mathrm{Rh}^{\mathrm{I}}$ NHC Catalysts: Carbonyl-Triggered Nonoxidative Mechanism. Organometallics 2017, 36, 2198-2207. (e) Azpíroz, R.; Di Giuseppe, A.; Passarelli, V.; Pérez-Torrente, J. J.; Oro, L. A.; Castarlenas, R. Rhodium-N-Heterocyclic Carbene Catalyzed Hydroalkenylation Reactions with 2-Vinylpyridine and 2-Vinylpyrazine: Preparation of Nitrogen-Bridgehead Heterocycles. Organometallics 2018, 37, 1695-1707. (f) Azpíroz, R.; Di Giuseppe, A.; Urriolabeitia, A.; Passarelli, V.; Polo, V.; Pérez-Torrente, J. J.; Oro, L. A.; Castarlenas, R. Hydride-Rhodium(III)-N-Heterocyclic Carbene Catalyst for Tandem Alkylation/Alkenylation via $\mathrm{C}-\mathrm{H}$ Activation. ACS Catal. 2019, 9, 9372-9386.

(17) (a) Rawson, J. M.; Winpenny, R. E. P. The Coordination Chemistry of 2-pyridone and its Derivatives. Coord. Chem. Rev. 1995, 139, 313-374. (b) Oro, L. A.; Ciriano, M. A.; Pérez-Torrente, J. J.; Villarroya, E. Controlling the Molecular Architecture of Low Nuclearity Rhodium and Iridium Complexes using Bridging N-C-X (X = N, O, S) Ligands. Coord. Chem. Rev. 1999, 193-195, 941-975. (c) Kempe, R. The Strained $\eta^{2}$-N-Amido- $N$-Pyridine Coordination of Aminopyridinato Ligands. Eur. J. Inorg. Chem. 2003, 2003, 791-803.

(18) (a) Breit, B.; Seiche, W. Hydrogen Bonding as a Construction Element for Bidentate Donor Ligands in Homogeneous Catalysis: Regioselective Hydroformylation of Terminal Alkenes. J. Am. Chem. Soc. 2003, 125, 6608-6609. (b) Kawahara, R.; Fujita, K.-i.; Yamaguchi, R. Cooperative Catalysis by Iridium Complexes with a Bipyridonate Ligand: Versatile Dehydrogenative Oxidation of 
Alcohols and Reversible Dehydrogenation-Hydrogenation between 2Propanol and Acetone. Angew. Chem., Int. Ed. 2012, 51, 1279012794. (c) Siek, S.; Burks, D. B.; Gerlach, D. L.; Thompson, C. R.; Qu, F.; Shankwitz, J. E.; Vasquez, R. M.; Chambers, N.; Szulczewski, G. J.; Grotjahn, D. B.; Webster, C. E.; Papish, E.; et al. Iridium and Ruthenium Complexes of N-Heterocyclic Carbene- and PyridinolDerived Chelates as Catalysts for Aqueous Carbon Dioxide Hydrogenation and Formic Acid Dehydrogenation: The Role of the Alkali Metal. Organometallics 2017, 36, 1091-1106.

(19) (a) Chong, E.; Brandt, J. W.; Schafer, L. L. 2-Pyridonate Tantalum Complexes for the Intermolecular Hydroaminoalkylation of Sterically Demanding Alkenes. J. Am. Chem. Soc. 2014, 136, 1089810901. (b) Wang, P.; Verma, P.; Xia, G.; Shi, J.; Qiao, J. X.; Tao, S.; Cheng, P. T. W.; Poss, M. A.; Farmer, M. E.; Yeung, K.-S.; Yu, J.-Q. Ligand-Accelerated non-Directed $\mathrm{C}-\mathrm{H}$ Functionalization of Arenes. Nature 2017, 551, 489-494. (c) Salamanca, V.; Toledo, A.; Albéniz, A. C. [2,2'-Bipyridin]-6(1H)-one, a Truly Cooperating Ligand in the Palladium-Mediated C-H Activation Step: Experimental Evidence in the Direct C-3 Arylation of Pyridine. J. Am. Chem. Soc. 2018, 140, 17851-17856. (d) Li, F.; Zhou, Y.; Yang, H.; Wang, Z.; Yu, Q.; Zhang, F. L. Monodentate Transient Directing Group Enabled PdCatalyzed Ortho-C-H Methoxylation and Chlorination of Benzaldehydes. Org. Lett. 2019, 21, 3692-3695. (e) Xiao, L. J.; Hong, K.; Luo, F.; Hu, L.; Ewing, W. R.; Yeung, K. S.; Yu, J. Q. Pd ${ }^{\mathrm{II}}$-Catalyzed Enantioselective $\mathrm{C}\left(\mathrm{sp}^{3}\right)$-H Arylation of Cyclobutyl Ketones Using a Chiral Transient Directing Group. Angew. Chem., Int. Ed. 2020, 59, 9594-9600.

(20) (a) Wang, R.; Ma, J.; Li, F. Synthesis of $\alpha$-Alkylated Ketones via Tandem Acceptorless Dehydrogenation/ $\alpha$-Alkylation from Secondary and Primary Alcohols Catalyzed by Metal-Ligand Bifunctional Iridium Complex $\left[\mathrm{Cp} * \operatorname{Ir}\left(2,2^{\prime}\right.\right.$-bpyO $\left.)\left(\mathrm{H}_{2} \mathrm{O}\right)\right]$. J. Org. Chem. 2015, 80, 1076910766. (b) Yan, X.; Ge, H.; Yang, X. Unexpected Concerted TwoProton Transfer for Amination of Formic Acid to Formamide Catalysed by Mn Bipyridinol Complexes. Catal. Sci. Technol. 2018, 8, 5735-5739. (c) Griffin, S. E.; Schafer, L. L. Vanadium Pyridonate Catalysts: Isolation of Intermediates in the Reductive Coupling of Alcohols. Inorg. Chem. 2020, 59, 5256-5260.

(21) (a) Flood, T. C.; Lim, J. K.; Deming, M. A. Generation of Coordinative Unsaturation at Osmium via Ring-Opening Equilibration of a 2-Pyridonato Chelate Complex. Organometallics 2000, 19, 2310-2317. (b) Royer, A. M.; Rauchfuss, T. B.; Gray, D. L. Organometallics 2010, 29, 6763-6768. (c) Clarkson, J. M.; Schafer, L. L. Bis(tert-butylimido)bis(N,O-chelate)tungsten(VI) Complexes: Probing Amidate and Pyridonate Hemilability. Inorg. Chem. 2017, $56,5553-5566$.

(22) (a) Wang, N.; Li, B.; Song, H.; Xu, S.; Wang, B. Investigation and Comparison of the Mechanistic Steps in the $\left[\left(\mathrm{Cp} * \mathrm{MCl}_{2}\right)_{2}\right]$ $\left(\mathrm{Cp} *=\mathrm{C}_{5} \mathrm{Me}_{5} ; \mathrm{M}=\mathrm{Rh}, \mathrm{Ir}\right)$-Catalyzed Oxidative Annulation of Isoquinolones with Alkynes. Chem. - Eur. J. 2013, 19, 358-364. (b) Munjanja, L.; Yuan, H.; Brennessel, W. W.; Jones, W. D. Synthesis, Characterization, and Reactivity of $\mathrm{Cp} * \mathrm{Rh}$ (III) Complexes Having Functional N,O Chelate Ligands. J. Organomet. Chem. 2017, $847,28-32$.

(23) (a) Boyd, D. C.; Szalapski, R.; Mann, K. R. Preparation, Characterization, and Structural Analyses of $[\mathrm{Rh}(\mathrm{chp})(\mathrm{NBD})]_{2}$ and $[\mathrm{Rh}(\mathrm{chp})(\mathrm{NBD})]_{2}\left(\mathrm{PF}_{6}\right)$. Isolation of a Paramagnetic $\mathrm{d}^{7}-\mathrm{d}^{8}$ Binuclear Radical and Its $\mathrm{d}^{8}-\mathrm{d}^{8}$ Precursor. Organometallics 1989, 8, 790-795. (b) Fandos, R.; Hernández, C.; Otero, A.; Rodríguez, A.; Ruiz, M. J.; García Fierro, J. L.; Terreros, P. Rhodium and Iridium Hydroxide Complexes $[\mathrm{M}(\mu-\mathrm{OH})(\mathrm{COD})]_{2}(\mathrm{M}=\mathrm{Rh}, \mathrm{Ir})$ as Versatile Precursors of Homo and Early-Late Heterobimetallic Compounds. X-ray Crystal Structures of $\mathrm{Cp}^{*} \mathrm{Ta}\left(\mu_{3}-\mathrm{O}\right)_{4}[\mathrm{Rh}(\mathrm{COD})]_{4} \quad\left(\mathrm{Cp}^{*}=\eta^{5}-\mathrm{C}_{5} \mathrm{Me}_{5}\right)$ and $\left[\operatorname{Ir}\left(2-\mathrm{O}-3-\mathrm{CN}-4,6-\mathrm{Me}_{2}-\mathrm{C}_{5} \mathrm{HN}\right)(\mathrm{COD})\right]_{2}$. Organometallics 1999, 18, 2718-2723. (c) Li, Z.; David, A.; Albani, B. A.; Pellois, J.-P.; Turro, C.; Dunbar, K. R. Optimizing the Electronic Properties of Photoactive Anticancer Oxypyridine-Bridged Dirhodium(II,II) Complexes. J. Am. Chem. Soc. 2014, 136, 17058-17070.

(24) (a) Spannenberg, A.; Oberthur, M.; Noss, H.; Tillack, A.; Arndt, P.; Kempe, R. Metal-Metal Communication of Rh or Pd with
$\mathrm{Nd}$ in Novel Heterobinuclear Complexes. Angew. Chem., Int. Ed. 1998, 37, 2079-2082. (b) Zamorano, A.; Rendón, N.; Valpuesta, J. E. V.; Álvarez, E.; Carmona, E. Synthesis and Reactivity toward $\mathrm{H}_{2}$ of $\left(\eta^{5}-\mathrm{C}_{5} \mathrm{Me}_{5}\right) \mathrm{Rh}(\mathrm{III})$ Complexes with Bulky Aminopyridinate Ligands. Inorg. Chem. 2015, 54, 6573-6581.

(25) (a) Deeming, A. J.; Hardcastle, K. I.; Meah, M. N.; Bates, P. A.; Dawes, H. M.; Hursthouse, M. B. Rhodium(III) Complexes with Pyridine-2-thiol (pySH) and Pyridine-2-thiolato (pyS) as the only Ligands: Crystal Structures of mer-[Rh(pyS),], [Rh(pyS)(pySH)]Cl. $0.5 \mathrm{H}_{2} 0$ and $[\mathrm{Rh}(\mathrm{pyS}),(\mathrm{pySH})]$. J. Chem. Soc., Dalton Trans. 1988, 227-233. (b) Seino, H.; Yoshikawa, T.; Hidai, M.; Mizobe, Y. Preparation of Mononuclear and Dinuclear Rh Hydrotris(pyrazolyl)borato Complexes Containing Arenethiolato Ligands and Conversion of the Mononuclear Complexes into Dinuclear $\mathrm{Rh}-\mathrm{Rh}$ and $\mathrm{Rh}-\mathrm{Ir}$ Complexes with Bridging Arenethiolato Ligands. Dalton Trans. 2004, 3593-3600. (c) Wang, H.; Guo, X.-Q.; Zhong, R.; Lin, Y.; Zhang, P.C.; Hou, X.-F. Reactions of Half-Sandwich Rhodium(III) and Iridium(III) Compounds with Pyridinethiolate Ligands: Mono-, di-, and tri-Nuclear Complexes. J. Organomet. Chem. 2009, 694, 33623368.

(26) Penfold, B. R. The Electronic Distribution in Crystalline $\alpha$ pyridone. Acta Crystallogr. 1953, 6, 591-600.

(27) Palacios, L.; Di Giuseppe, A.; Castarlenas, R.; Lahoz, F. J.; Pérez-Torrente, J. J.; Oro, L. A. Pyridine versus Acetonitrile Coordination in Rhodium-N-Heterocyclic Carbene Square-Planar Complexes. Dalton Trans. 2015, 44, 5777-5789.

(28) Feuerstein, M.; Chahen, L.; Doucet, H.; Santelli, M. Efficient Synthesis of Enynes by Tetraphosphine-Palladium Catalysed Reaction of Vinyl Bromides with Terminal Alkynes. Tetrahedron 2006, 62, $112-120$.

(29) (a) Timpa, S. D.; Zhou, J.; Bhuvanesh, N.; Ozerov, O. V. Potential Carbon-Fluorine Reductive Elimination from PincerSupported $\mathrm{Rh}(\mathrm{III})$ and Dominating Side Reactions: Theoretical and Experimental Examination. Organometallics 2014, 33, 6210-6217. (b) Jurt, P.; Salnikov, O. G.; Gianetti, G. L.; Chukanov, N. V.; Baker, M. G.; Le Corre, G.; Borger, J. E.; Verel, R.; Gauthier, S.; Fuhr, O.; Kovtunov, K. V.; Fedorov, A.; Fenske, D.; Koptyug, V.; Grützmacher, $\mathrm{H}$. Low-Valent Homobimetallic Rh Complexes: Influence of Ligands on the Structure and the Intramolecular Reactivity of Rh-H Intermediates. Chem. Sci. 2019, 10, 7937-7945.

(30) Gómez-Gallego, M.; Sierra, M. A. Kinetic Isotope Effects in the Study of Organometallic Reaction Mechanisms. Chem. Rev. 2011, $111,4857-4963$

(31) (a) Royer, A. M.; Rauchfuss, T. B.; Wilson, S. R. Coordination Chemistry of a Model for the GP Cofactor in the Hmd Hydrogenase: Hydrogen-Bonding and Hydrogen-Transfer Catalysis. Inorg. Chem. 2008, 47, 395-397.

(32) $\mathrm{A} \mathrm{Rh}^{\mathrm{I}}$ square-planar intermediate $\mathrm{E}$ ', similar to $\mathbf{E}$ but bearing mutually cis $\pi$-alkyne molecules, was found to be more stable. However, the CMD step originated from the new isomer E', presents a transition state TSEF' of $26.3 \mathrm{kcal} \mathrm{mol}^{-1}$, significantly higher than TSEF (15.9 $\mathrm{kcal} \mathrm{mol}^{-1}$ ) (see Figure S107 in the Supporting Information).

(33) (a) Gellrich, U.; Mei $\beta$ ner, A.; Steffani, A.; Kähny, M.; Drexler, H.-J.; Heller, D.; Plattner, D. A.; Breit, B. Mechanistic Investigations of the Rhodium Catalyzed Propargylic $\mathrm{CH}$ Activation. J. Am. Chem. Soc. 2014, 136, 1097-1104. (b) Zhang, H.; Bao, X. Computational insight into the mechanism of the $\mathrm{Pd}(0)$-Brønsted acid cooperatively catalysed head-to- tail dimerization of terminal alkynes. RSC Adv. 2015, 5, 84636-84642.

(34) Yu, X.-Y.; Patrick, B. O.; James, B. R. Rhodium(III) Peroxo Complexes Containing Carbene and Phosphine Ligands. Organometallics 2006, 25, 4870-4877.

(35) SAINT+: Area-Detector Integration Software, version 6.01; Bruker AXS: Madison, WI, 2001.

(36) Sheldrick, G. M. SADABS Program; University of Götingen: Göttingen, Germany, 1999.

(37) Sheldrick, G. M. SHELXS 97, Program for the Solution of Crystal Structure; University of Göttingen: Göttingen, Germany, 1997. 
(38) Sheldrick, G. M. Crystal Structure Refinement with SHELXL. Acta Crystallogr., Sect. C: Struct. Chem. 2015, 71, 3-8.

(39) Farrugia, L. J. WinGX and ORTEP for Windows: an Update. J. Appl. Crystallogr. 2012, 45, 849-854.

(40) Firsch, M. J.; Trucks, G. W.; Schlegel, H. B.; Scuseria, G. E.; Robb, M. A.; Cheeseman, J. R.; Scalmani, G.; Barone, V.; Mennucci, B.; Petersson, G. A.; Nakatsuji, H.; Caricato, M.; Li, X.; Hratchian, H. P.; Izmaylov, A. F.; Bloino, J.; Zheng, G.; Sonnenberg, J. L.; Hada, M.; Ehara, M.; Toyota, K.; Fukuda, R.; Hasegawa, J.; Ishida, M.; Nakajima, T.; Honda, Y.; Kitao, O.; Nakai, H.; Vreven, T.; Montgomery, J. A., Jr.; Peralta, J. E.; Ogliaro, F.; Bearpark, M.; Heyd, J. J.; Brothers, E.; Kudin, K. N.; Staroverov, V. N.; Kobayashi, R.; Normand, J.; Raghavachari, K.; Rendell, A.; Burant, J. C.; Iyengar, S. S.; Tomasi, J.; Cossi, M.; Rega, N.; Millam, J. M.; Klene, M.; Knox, J. E.; Cross, J. B.; Bakken, V.; Adamo, C.; Jaramillo, J.; Gomperts, R.; Stratmann, R. E.; Yazyev, O.; Austin, A. J.; Cammi, R.; Pomelli, C.; Ochterski, J. W.; Martin, R. L.; Morokuma, K.; Zakrzewski, V. G.; Voth, G. A.; Salvador, P.; Dannenberg, J. J.; Dapprich, S.; Daniels, A. D.; Farkas, Ö.; Foresman, J. B.; Ortiz, J. V.; Cioslowski, J.; Fox, D. J. Gaussian 09, revision D.1; Gaussian, Inc., Wallingford, CT, 2004.

(41) (a) Becke, A. D. Density-Functional Thermochemistry. V. Systematic Optimization of Exchange-Correlation Functionals. J. Chem. Phys. 1997, 107, 8554-8560. (b) Grimme, S.; Ehrlich, S.; Goerigk, L. Effect of the Damping Function in Dispersion Corrected Density Functional Theory. J. Comput. Chem. 2011, 32, 1456-1465.

(42) Weigend, F. R.; Ahlrichs, R. Balanced Basis Sets of Split Valence, Triple Zeta Valence and Quadruple Zeta Valence Quality for $\mathrm{H}$ to Rn: Design and Assessment of Accuracy. Phys. Chem. Chem. Phys. 2005, 7, 3297-3305.

(43) Zhao, Y.; Truhlar, D. G. A New Local Density Functional for Main-group Thermochemistry, Transition Metal Bonding, Thermochemical Kinetics, and Noncovalent Interactions. J. Chem. Phys. 2006, 125, 194101.

(44) Marenich, A. V.; Cramer, C. J.; Truhlar, D. G. Universal Solvation Model Based on Solute Electron Density and on a Continuum Model of the Solvent Defined by the Bulk Dielectric Constant and Atomic Surface Tensions. J. Phys. Chem. B 2009, 113, 6378-6396.

(45) Bryantsev, V. S.; Diallo, M. S.; Goddard, W. A., III Calculation of Solvation Free Energies of Charged Solutes Using Mixed Cluster/ Continuum Models. J. Phys. Chem. B 2008, 112, 9709-9719. 